\title{
Big Data-Based Boring Indexes and Their Application during TBM Tunneling
}

\author{
Shuangjing Wang $\left(\mathbb{D},{ }^{1,2,3}\right.$ Yujie Wang $\mathbb{D}^{1,3}$ Xu Li ${ }^{1},{ }^{4}$ Lipeng Liu, ${ }^{1,3}$ Hai Xing, ${ }^{5}$ \\ and Yunpei Zhang ${ }^{1,3}$ \\ ${ }^{1}$ State Key Laboratory of Simulation and Regulation of Water Cycle in River Basin, \\ China Institute of Water Resources and Hydropower Research, Beijing 100038, China \\ ${ }^{2}$ College of Civil and Transportation Engineering, Hohai University, Nanjing 210098, Jiangsu, China \\ ${ }^{3}$ Department of Geotechnical Engineering, China Institute of Water Resources and Hydropower Research, Beijing 100038, China \\ ${ }^{4}$ Key Laboratory of Urban Underground Engineering of Ministry of Education, Beijing Jiaotong University, Beijing 100044, China \\ ${ }^{5}$ Sinohydro Bureau 6 Co., Ltd., Shenyang 110179, Liaoning, China
}

Correspondence should be addressed to Yujie Wang; geyjwang@foxmail.com

Received 29 June 2021; Revised 15 August 2021; Accepted 1 September 2021; Published 24 September 2021

Academic Editor: DongDong Ge

Copyright (c) 2021 Shuangjing Wang et al. This is an open access article distributed under the Creative Commons Attribution License, which permits unrestricted use, distribution, and reproduction in any medium, provided the original work is properly cited.

\begin{abstract}
Tunnel boring machine (TBM) tunneling data have been extensively collected to utilize TBM information technology by analyzing and mining the data for achieving a safe and efficient TBM tunneling. Feature extraction of big data could reduce the complexity for problems, but conventional indexes based on feature extraction, such as field penetration index (FPI), specific penetration (SP), and boreability index (BI), have some disadvantages. Thus, we present novel boring indexes derived from tunneling data in the Yinchao TBM project. Linear thrust-penetration and torque-penetration relationships in filtered ascending sections $(p \geq 2 \mathrm{~mm} / \mathrm{r}$ ) are proposed using statistical features and through physical mechanism analysis of parameters in the TBM cyclic tunneling process. Boring indexes, such as normal boring difficulty index, initial rock mass fragmentation difficulty index, and tangential boring difficulty index, are defined using the coefficients of the linear thrust-penetration and torque-penetration relationships. Subsequently, the defined boring indexes are verified using performance prediction of 291 cyclic tunneling processes. Finally, a preliminary application of support measure suggestions is conducted using the statistical features of boring indexes, where certain criteria are proposed and verified. The results showed that the criterion of boring indexes for support measure suggestions could achieve a reasonable confirmation, potentially providing quantitative quotas for support measure suggestions in the subsequent construction process.
\end{abstract}

\section{Introduction}

Tunnel boring machines (TBMs), a type of engineering machinery, have been widely applied in the construction of tunnels, such as water conveyance, highway, and railway tunnels [1]. With the development of information technology [2] and construction of big data management platforms [1], the Internet of Things technology for real-time TBM data acquisition has been used widely. The method for data acquisition has been used in the Yinsong TBM project $[3,4]$ for effectively recording extensive data, including cutterhead thrust, cutterhead torque, cutterhead rotation speed, advance rate, and penetration, which are closely related to rock mass fragmentation $[5,6]$. Therefore, the analyzing and mining of TBM tunneling data can provide valuable information regarding the rock mass [7].

TBM tunneling can be regarded as a large-scale field linear cutting test [8]. The main characteristics of rock mass fragmentation are the interaction between the TBM cutters and rock mass, as well as loading the thrust and torque of the cutterhead acting on the rock mass, which exceeds the ultimate strength of the rock mass [9]. The performance 
parameters are closely related to both the physical and operational parameters of the rock mass; some of the related studies in F- $p$ and $T-p$ relationships are [10-18]. Based on the studies, many indexes have been derived from TBM performance parameters to reflect the characteristics of rock mass. Some of the proposed indexes are the field penetration index (FPI) [19], specific penetration (SP) [20], boreability index (BI) [5], and drilling efficiency index (TPI) [4], which can be used for rock mass parameter prediction [21], rock mass classification [22], and adverse geological diagnosis [4]. In addition, they can achieve better results based on the fine relationships of thrust-penetration $(F-p)$ and torque-penetration $(T-p)$. Regarding the $F-p$ and $T-p$ relationships, a linear relationship between the normal force, rolling force, and penetration was proposed in [6] using a stepwise test on a linear cutting machine [23]; they concluded a comparable linear relationship under different confining stresses. In field tunneling tests, Liujie et al. [24] demonstrated the effectiveness of the linear $F-p$ relationship using field-stepped tunneling tests in limestone strata. Existing studies considered the $F-p$ and $T$ - $p$ relationships, providing simple, but convenient, methods to describe the TBM parameters. However, determining a linear relationship coefficient for different rock masses has many disadvantages. First, the laboratory tests make many simplifications; thus, the obtained results might not be appropriate for field tunneling. Second, the $F-p$ and $T-p$ relationships are acquired using repeated stepped tunneling tests by adjusting different penetrations that are not appropriate for continuous field tunneling. Therefore, field tunneling data to determine the $F-p$ and $T$ - $p$ relationships for rock mass evaluation should be easy to acquire and have robust features, which are crucial for improving the precision of relationships.

TBM big data had been collected during tunneling, from which we could obtain valuable information about the rock mass through data mining. However, an excessive amount of TBM tunneling data would increase the complexity of the problems, relationship analysis, and comprehensive index extraction from big data, which could be helpful in decreasing the complexity. Conventional methods for the determination of the $F-p$ and $T$ - $p$ relationships have the abovementioned disadvantages; therefore, comprehensive index extraction may not yield a high accuracy. Big data could provide sufficient proof about the $F-p$ and $T-p$ relationships and obtain acceptable results for comprehensive index extraction. The key contribution of this study is proposing a novel model and data hybrid-driven boring indexes in cyclic tunneling processes, followed by a preliminary application for support measure suggestions.

This study introduces novel indexes for reflecting the process of rock mass fragmentation, which differ from conventional indexes, such as FPI and SP. Subsequently, a preliminary application is adopted for support measure suggestions. The remainder of this paper is organized as follows. Section 2 describes the project and TBM and the flowchart of this study. Section 3 describes the parameter characteristics during TBM tunneling. Section 4 introduces novel boring indexes and corresponding calculation methods. Section 5 presents a preliminary application of boring indexes for support measure suggestions. Section 6 discusses the application of the presented boring indexes. Finally, Section 7 presents the conclusion of the study.

\section{Description of the Project and Study Flowchart}

2.1. Project Overview. Chaoer River to Xiliao River water conveyance project (Yinchao TBM project) is located in the Hinggan League, northeast Inner Mongolia Autonomous Region of China, with a total length of $173.76 \mathrm{~km}$ from chainage $\mathrm{K} 0+000$ to $\mathrm{K} 173+760$ and a maximum water conveyance flow of 488 million $\mathrm{m}^{3}$ per year. Tunnel \#2 has a length of $58.5 \mathrm{~km}$ from chainage $\mathrm{K} 10+300$ to $\mathrm{K} 68+805$. The TBM tunnel construction started on $9 / 20 / 2020$, and $2.42 \mathrm{~km}$ between chainages $\mathrm{K} 66+138$ and $\mathrm{K} 63+718$ had been completed within 3 months. The main lithologies in the constructed tunnel are Jurassic tuff, Jurassic lava, and Yanshanian granite, with a mean overburden depth of approximately $70 \mathrm{~m}$, as shown in Figure 1.

During the tunneling process, some adverse geology conditions, such as fault fracture zone and weak rock mass, exist. Rock reinforcement measures, such as rock bolt supports [25] (Figure 2) and steel rib supports [26] (Figure 3), are widely used to improve the safety against adverse geology conditions. A total of 4 steel rib and 25 rock bolt support measures were recorded completely in the studied sections $(2.42 \mathrm{~km})$, whereas all support measures were several meters long. Based on the statistical features of actual support measures and proposed boring indexes in this study, quantitative advice could be provided for support measure suggestions.

2.2. TBM Overview. Figure 4 shows that the main TBM specifications include a diameter of $5.2 \mathrm{~m}, 34$ cutters, a data acquisition frequency of $1 \mathrm{~Hz}$, and other specifications, as listed in Table 1. The cutterhead thrust refers to the loading of a cylinder, which includes the valid rock mass fragmentation thrust on the rock mass and the friction thrust to overcome the friction of pulling the auxiliary equipment. So, a field tunneling test was conducted to determine the friction torque and thrust during the shield friction tests [5], and the valid rock mass fragmentation thrust (torque) could be calculated through total thrust (torque) subtracting to friction thrust (torque).

2.3. Study Flowchart. To obtain novel boring indexes based on TBM big data, a flowchart is proposed, as shown in Figure 5. The three main steps are (1) data processing (used for data production), (2) proposed boring indexes (demonstrating the methods and including the verification of the proposed boring indexes), and (3) application of boring indexes in support measure suggestions.

\section{Parameter Characteristics during the TBM Cyclic Tunneling Process}

In this study, the analysis of parameter characteristics during a cyclic tunneling process is conducted, linear $F-p$ and $T-p$ relationships in the ascending section are proposed, and a 


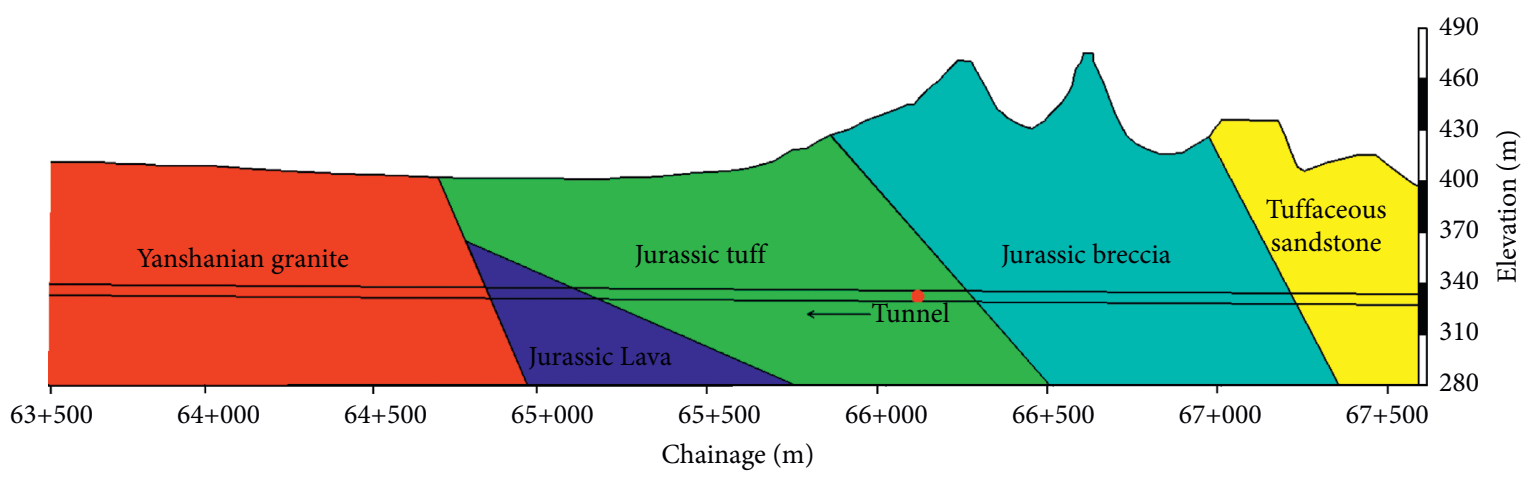

FIGURE 1: Stratigraphic profile of the study region.

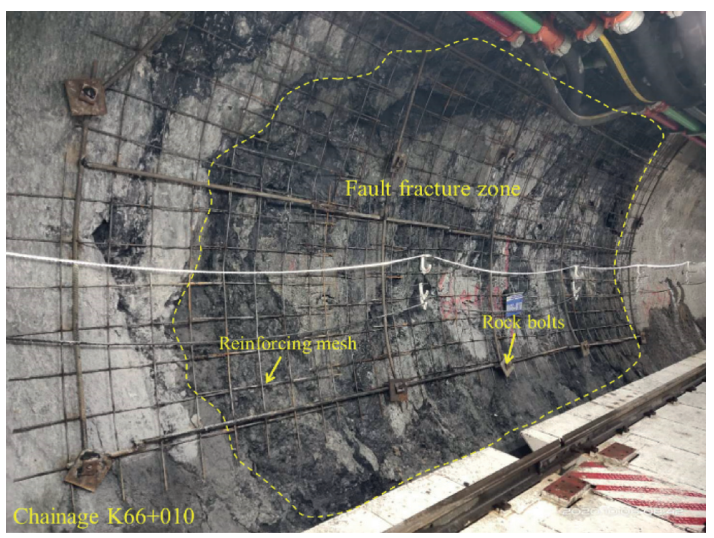

(a)

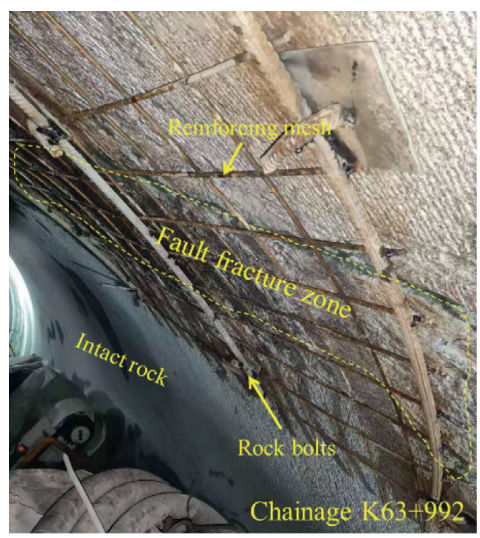

(b)

FIGURE 2: Rock bolt supports during adverse geology conditions: (a) fault fracture zone in chainage K66 + 010 and (b) fault fracture zone in chainage K63+992.

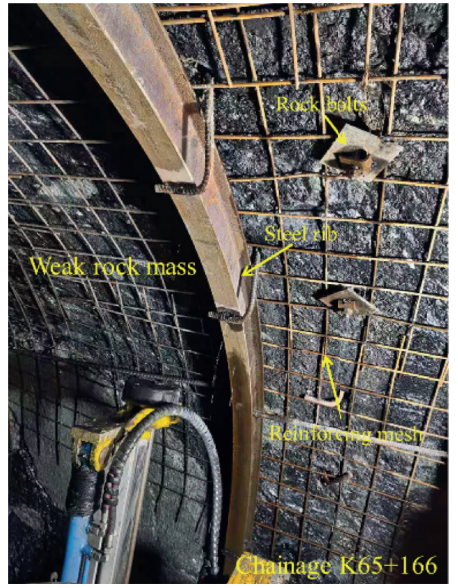

(a)

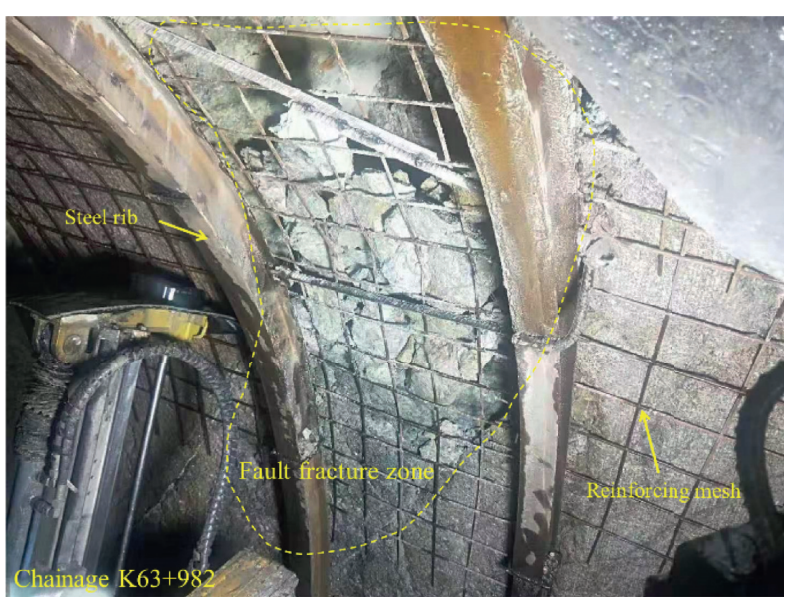

(b)

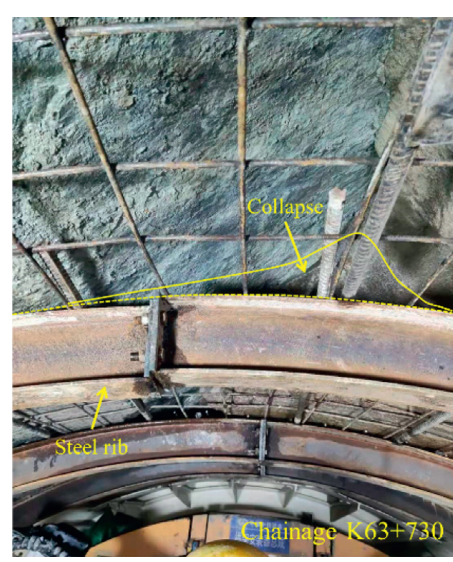

(c)

FIGURE 3: Steel rib supports during adverse geology conditions: (a) weak rock mass in chainage K65 + 166, (b) fault fracture zone in chainage $\mathrm{K} 63+982$, and (c) collapse in chainage K63 +730 .

physical mechanism is introduced to verify the relationships. Subsequently, a data processing method is proposed based on the parameter characteristic analysis for achieving a better cyclic segmentation.
3.1. Main Rock Mass Fragmentation Parameters during the TBM Operation. In general, the main parameters reflecting the characteristics of the TBM tunneling process include the rotation speed, advance rate, penetration (denoted as $p$ 


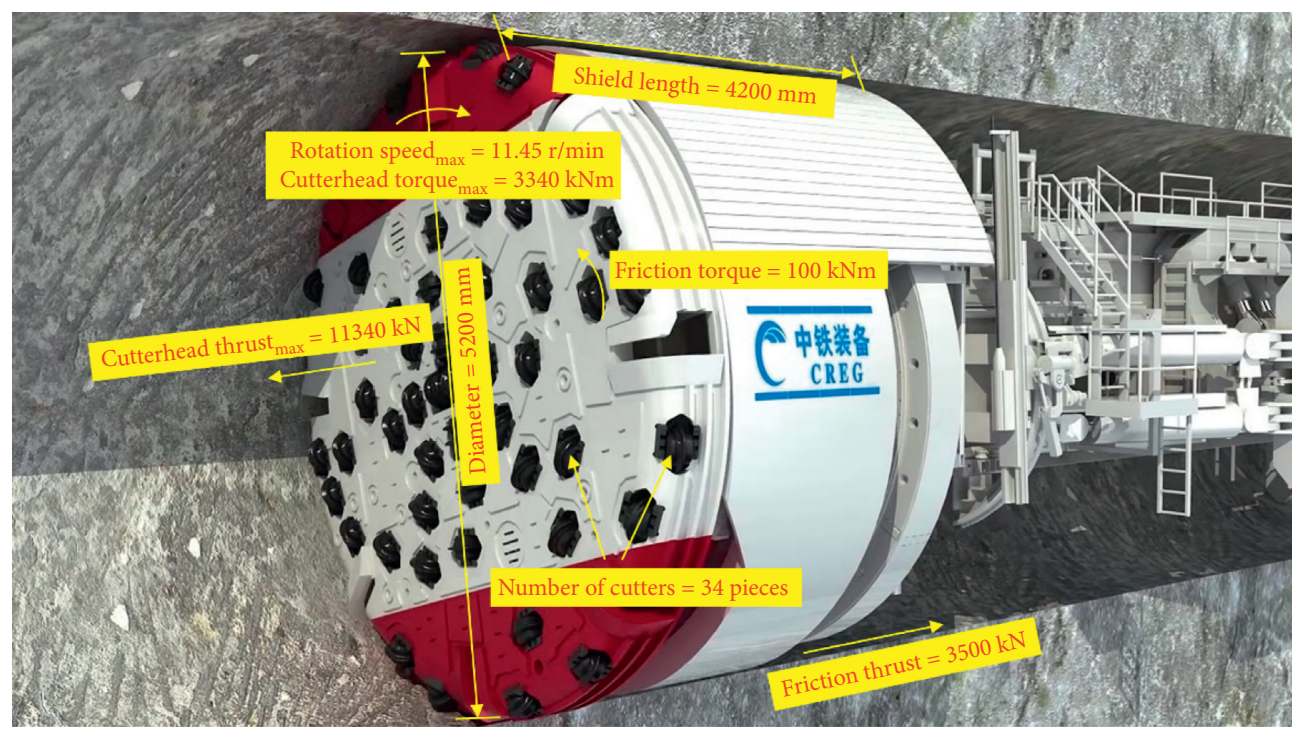

FIgURE 4: Schematic of the TBM [24].

TABLE 1: Main TBM specifications.

\begin{tabular}{lc}
\hline Parameters & Values \\
\hline Type & Open TBM \\
Number of cutters, $N$ & 34 pieces \\
Cutterhead diameter, $D$ & $5,200 \mathrm{~mm}$ \\
Maximum cutterhead thrust, $F$ & $11,340 \mathrm{kN}$ \\
Maximum cutterhead torque, $T$ & $3,340 \mathrm{kNm}$ \\
Maximum rotation speed, $n$ & $11.45 \mathrm{r} / \mathrm{min}$ \\
Maximum advance rate, $\mathrm{v}$ & $120 \mathrm{~mm} / \mathrm{min}$ \\
Maximum propel stroke, $\mathrm{L}$ & $1,800 \mathrm{~mm}$ \\
Shield length, $L_{S}$ & $4,200 \mathrm{~mm}$ \\
Data collection frequency, $f$ & $1 \mathrm{~Hz}$ \\
Friction torque, $T_{f}$ & $100 \mathrm{kNm}$ \\
Friction thrust, $F_{f}$ & $3500 \mathrm{kN}$ (total) $/ 100 \mathrm{kN}$ (single) \\
\hline
\end{tabular}

[mm/r] and expressed as $p=v / n)$, cutterhead thrust, and cutterhead torque. The rock mass is effectively broken under a preset cutterhead rotation speed (denoted as $n \_s e t[\mathrm{r} / \mathrm{min}]$ ) and advance rate (denoted as $v_{-}$set [\%]) by the TBM operators and action of $F$ and $T$ by the TBM driver systems. Therefore, operational and performance parameters are acquired. The realization process is as follows.

Operational parameters (active parameters), including cutterhead rotation speed and advanced rate, are the main controlling parameters. By adjusting performance parameters (passive parameters), such as $n \_s e t$ and $v \_s e t$, the cutters penetrate the rock mass under the action of $F$ and $T$. The values of performance parameters reflect the resistance of rock mass fragmentation at a certain $p$, which can be expressed as $F$ and $T=f(p)$ [27] for the same rock mass.

\subsection{Parameter Characteristics and Section Segmentation for} Typical TBM Cyclic Tunneling. Figure 6 shows the parameter characteristics of a typical TBM cyclic tunneling process, which includes processes among $n, n \_s e t, v, v \_s e t, F$, and $T$, where the $x$-axis and $y$-axis represent the time and the parameter values. Four sections were acquired in one cyclic tunneling process according to changes in parameter characteristics $[4,28]$, including idling, ascending, stable, and descending sections.

The parameter characteristics in each section are described as follows:

(a) Idling section: the startup process of the cutterhead with an increasing $n$ and $v$ is accompanied by no effective rock mass fragmentation. This process is an invalid rock mass fragmentation process.

(b) Ascending section: $n$ and $n \_$set remain constant, whereas $v, p, F$, and $T$ gradually increase with an increasing $v_{-}$set. Interaction in the TBM rock is gradually accompanied by an effective rock mass fragmentation, whereas this section lasts $2-5 \mathrm{~min}$ with a propel stroke of $100-200 \mathrm{~mm}$, during which the rock mass rarely changes. Furthermore, this section has two features according to the fluctuation of different parameters at approximately $220 \mathrm{~s}$. Prior to that, $F$ and $T$ increase with few fluctuations, but they also increase with severe fluctuations. The corresponding cutterhead thrust is denoted by $F_{\mathrm{b}}$. The first and second stages in the ascending section are introduced to describe the features. This process is a valid rock mass fragmentation process.

(c) Stable section: $n \_$set and $v \_s e t$ remain constant, the same as other parameters; however, they exhibit some fluctuations until the maximum propel stroke. This is the main rock mass fragmentation process during cyclic tunneling [3]. This process is a valid rock mass fragmentation process.

(d) Descending section: at the end of a cyclic tunneling, each parameter gradually decreases, and the cutterhead continues to rotate for a short period to clean the muck in the cutterhead until the maximum propel stroke. Subsequently, the TBM operators stop 


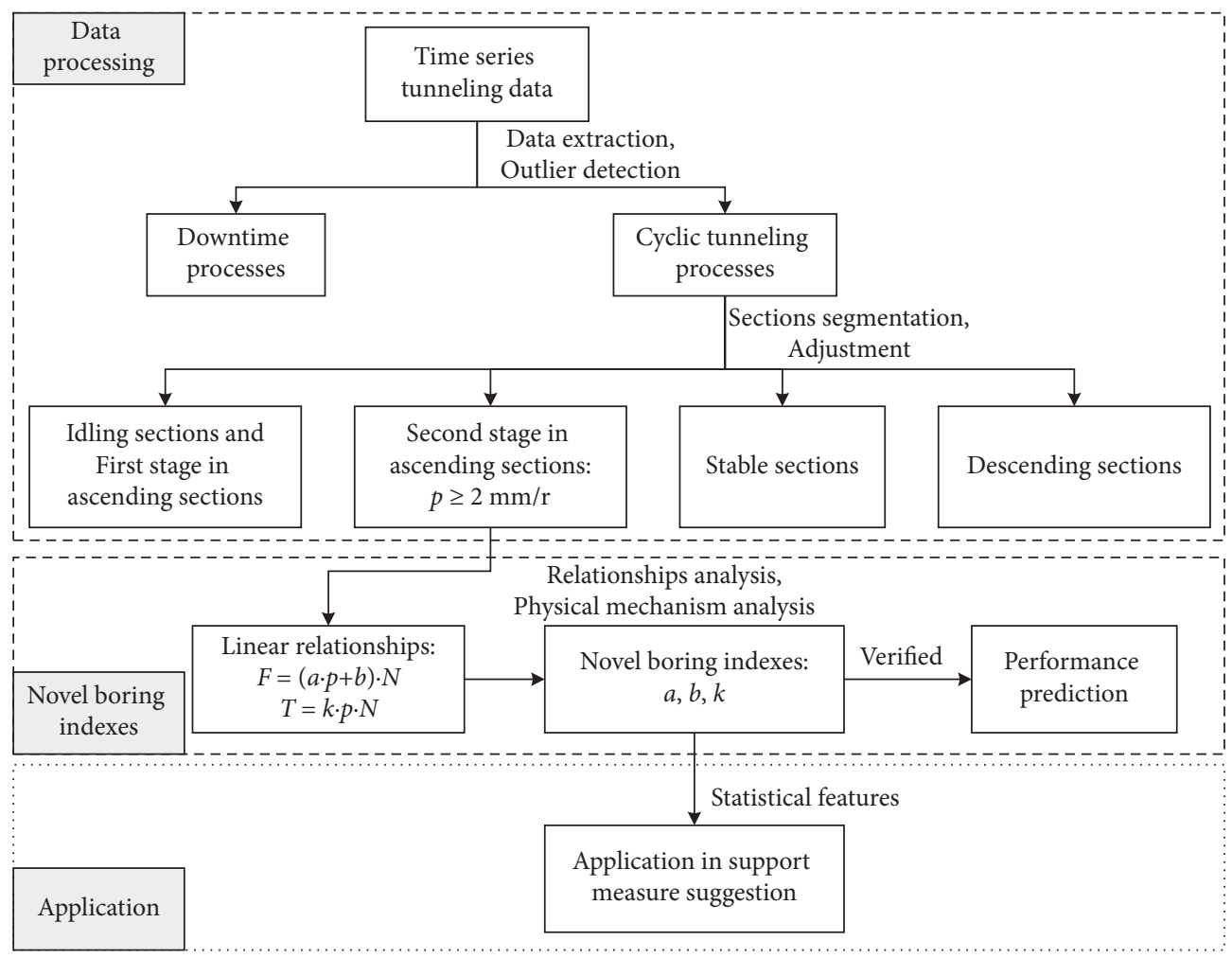

FIgUre 5: Study flowchart.

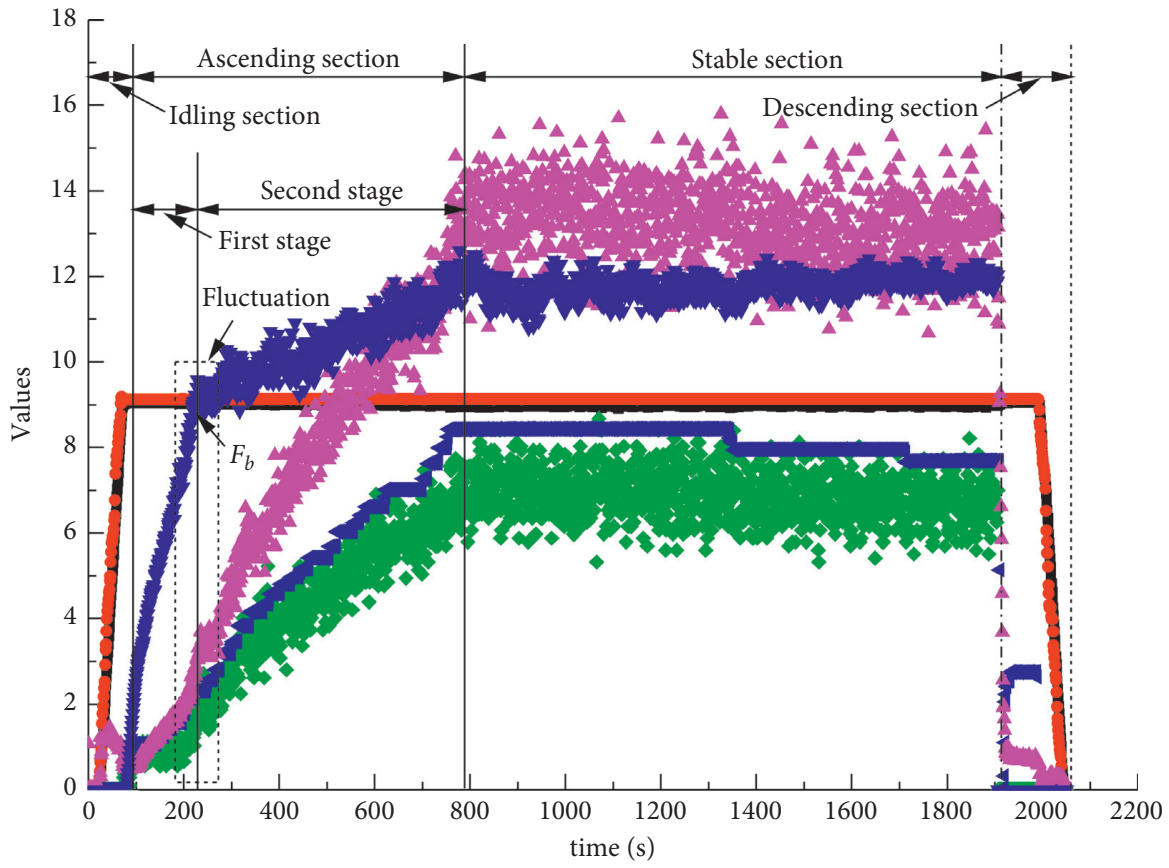

- $\mathrm{n}(\mathrm{r} / \mathrm{min})$

- $\mathrm{n} \_$set $(\mathrm{r} / \mathrm{min})$

- $\mathrm{v} / 10(\mathrm{~mm} / \mathrm{min})$
4 v_set $/ 5(\%)$

- $\mathrm{T} / 100(\mathrm{kNm})$

- $\mathrm{F} / 800(\mathrm{kN})$

FIgURE 6: Parameter characteristics during a typical TBM cyclic tunneling. 
the machine, retract the propel pumps, and prepare for the next cyclic tunneling. This process is an invalid rock mass fragmentation process.

3.3. Relationship between Different Parameters. Figure 7 shows the $F-p$ and $T-p$ relationships from the ascending and stable sections in the valid tunneling process shown in Figure 6.

Two linear $F-p$ relationships exist according to the fluctuations in the ascending section [20]: one has a higher $F$ - $p$ slope in the first stage, but $F$ fluctuates rarely, and the majority of $p$ is less than $2 \mathrm{~mm} / \mathrm{r}$. The other has a lower $F-p$ slope [24] in the second stage, whereas $F$ fluctuates severely and the slope is less than the former (here, $p$ exceeds $2 \mathrm{~mm} / \mathrm{r}$ and $F$ exceeds $6,900 \mathrm{kN}$ ). In the stable section, the $F-p$ relationship has a spindle shape, whereas $p$ fluctuates more than $F$ does. The linear $F$ - $p$ relationship of the second stage in the ascending section could reflect the $F$ - $p$ relationship in the stable section, whereas the $F-p$ relationship of the first stage in the ascending section could not. Therefore, the second linear $F$ - $p$ relationship reflects the valid rock mass fragmentation process and the stable section is a special process of the second stage in the ascending section. The $T-p$ relationship is linear in all ascending sections [4], and the intercept can be ignored. In summary, the linear $F-p$ and $T-p$ relationships of the second stage in the ascending section can reflect the general trend of the entire section during the valid rock mass fragmentation process based on the statistical features.

\subsection{Physical Mechanism Analysis for Parameter} Characteristics. Two processes related to the two stages in the ascending section are defined from the perspective of the physical mechanism during rock mass fragmentation (referred to as the initial TBM-rock interaction process and valid rock mass fragmentation process, respectively) to illustrate the parameter fluctuation characteristics of the two stages in the ascending section, as shown in Figure 6.

3.4.1. Initial TBM-Rock Interaction Process. Two principles can be used to explain the initial TBM-rock interaction process. The first principle proposed a crushed zone [9] in the interaction of TBM rock in the early stages; the rock mass would not break unless the loading was greater than the ultimate strength [29]. The second principle proposed the footing bearing capacity [30], which regarded the rock mass as a footing. The rock mass was broken when the rock penetration pressure was greater than the bearing capacity, which is a function of physical parameters, such as cohesion (c) and internal friction angle $(\varphi)$, as shown in Figures 8(a) and $8(\mathrm{c})$.

3.4.2. Valid Rock Mass Fragmentation Process. In the valid rock mass fragmentation process, the rock mass is broken under the interaction of the normal force (denoted by $F_{n}$, provided by $F$ ) and tangential force (denoted by $F_{r}$, provided by $T$ ) of the cutters, as shown in Figures $8(\mathrm{~b})$ and $8(\mathrm{~d})$ and expressed in the following equation:

$$
\left\{\begin{array}{l}
F_{n}=\frac{F-F_{f}}{N}, \\
F_{r}=\frac{\left(T-T_{f}\right)}{\sum_{i=1}^{N} R_{i}},
\end{array}\right.
$$

where $T_{f}$ is the friction torque, $F_{f}$ is the friction thrust, $N$ is the number of cutters in the cutter head, and $R_{i}$ is the radius of cutters installed in the cutter head.

For the disc cutter, Rostami and Ozdemir [31] defined the rock mass fragmentation force as the product of the uniaxial compressive strength and interaction area in the normal and tangential directions, as expressed in (2) and shown in Figure 9.

$$
\left\{\begin{array}{l}
F_{n}=A_{1} \cdot U C S=w \cdot \sqrt{2 r p-p^{2} \cdot U C S} \\
F_{r}=A_{2} \cdot U C S=w \cdot p \cdot U C S .
\end{array}\right.
$$

As shown in Figure 9, when $p$ is greater than $2 \mathrm{~mm} / \mathrm{r}$ and less than $10 \mathrm{~mm} / \mathrm{r}$, an acceptable linear relationship exists between $F_{n}$ and $F_{r}$ with an increasing $p$, indicating a linear relationship among $F_{r}, F_{n}, F$, and $T$.

3.5. Data Processing. After performing the parameter characteristic analysis in cyclic tunneling processes, a data processing method is proposed, which includes data extraction, section segmentation, and adjustment of ascending sections.

3.5.1. Data Extraction. Data extraction was aimed to extract cyclic tunneling data and downtime processes from time series TBM tunneling data, as shown in Figure 10. The cyclic tunneling processes are the main rock mass fragmentation processes, and the downtime processes are invalid fragmentation processes. For the extraction of cyclic tunneling processes, a comprehensive judgment method is adopted, which combines the TBM operational features when $F, T, n$, and $v$ are greater than zero, as expressed in (3). Therefore, cyclic tunneling processes are obtained using (4) when $C$ is greater than 0 , and the downtime processes are obtained when $C$ is less than or equal to 0 .

$$
\begin{aligned}
& C=n \cdot v \cdot F \cdot T, \\
& \left\{\begin{array}{l}
C>0, \quad \text { cyclic tunneling processes, } \\
C \leq 0, \quad \text { downtime processes. }
\end{array}\right.
\end{aligned}
$$

3.5.2. Outlier Detection. In general, main parameters would run under the maximum values, as presented in Table 1. However, there may exist some outliers owing to the sensor breakdown or other reasons, such as the outlier of $v$ [32]; however, it could not break the tunneling processes. Other parameters such as the outlier of $T$ would break the 


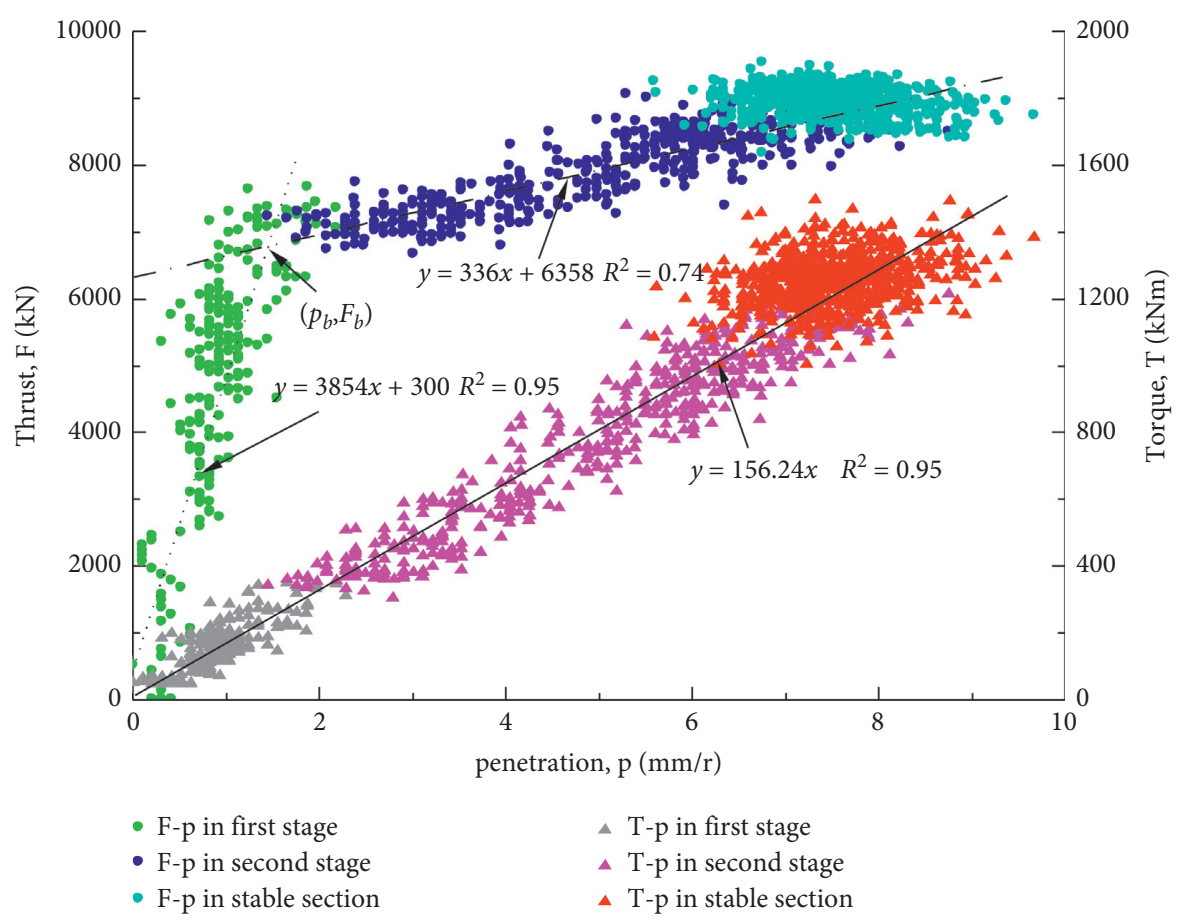

FIGURE 7: Correlation between different parameters during a cyclic tunneling.

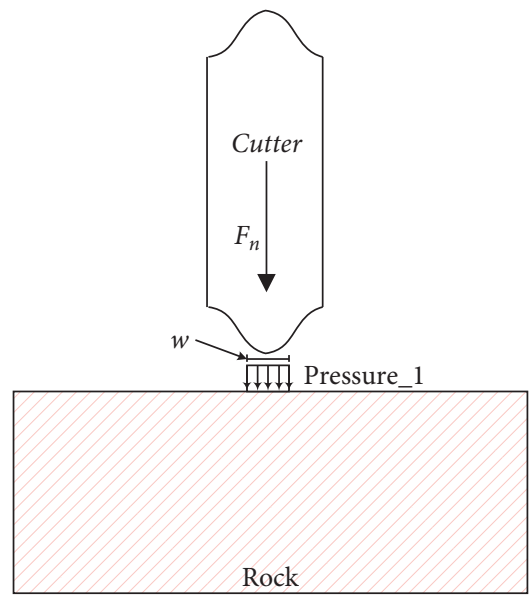

(a)

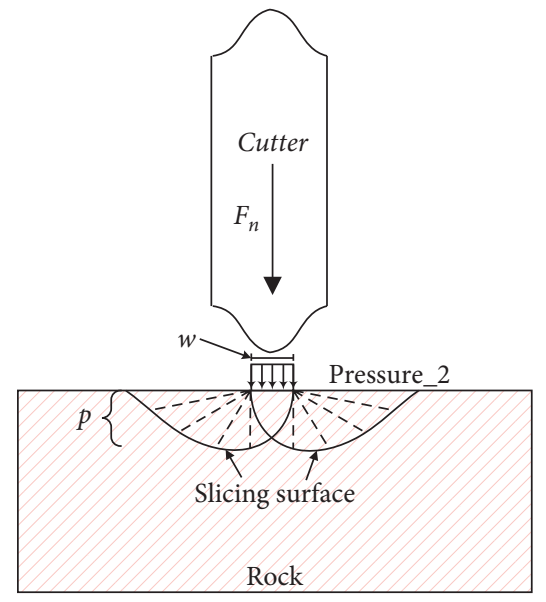

(b)

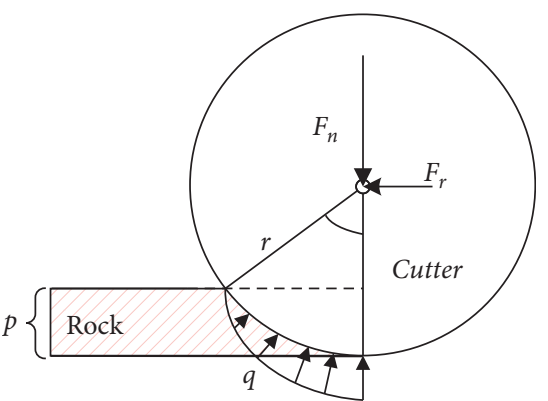

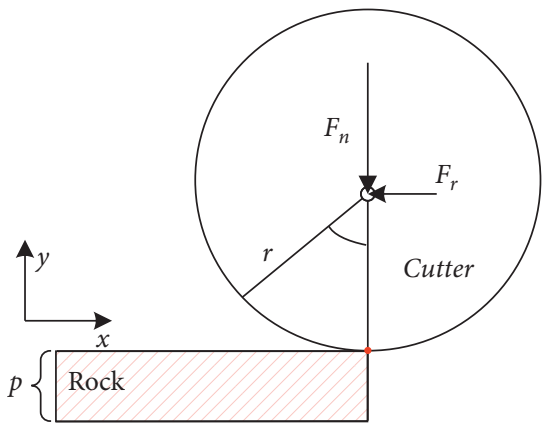

(c)

(d)

Figure 8: Schematic of bearing capacity by disc cutter (modified from [30, 31]). (a) Initial TBM-rock interaction. (b) Valid rock mass fragmentation (front view). (c) Initial TBM-rock interaction (side view). (d) Valid rock mass fragmentation (side view). $(F)_{n}$ is the normal force, $(F)_{r}$ is the tangential force, $(r)$ is the radius of the cutter, and $(q)$ is the distribution of the resultant force. Pressure_ 2 is the ultimate strength of the rock mass, and pressure_1 is less than the ultimate strength. 


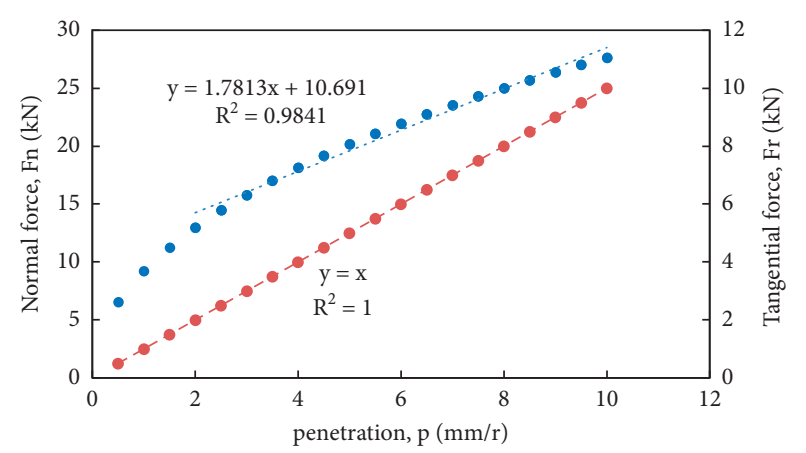

- Normal force,Fn

- Tangential force, Fr

FIGURE 9: Relationships between the force and penetration (supposing $U C S=1$ and $w=1$ in equation (2)).

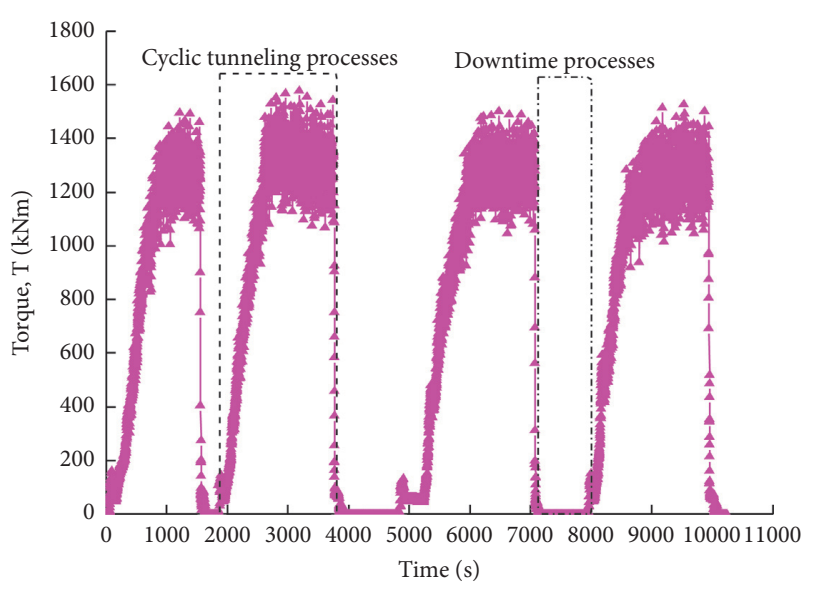

FIgUre 10: Time series TBM tunneling data.

tunneling processes because of the maximum electric current of motors [28]. Therefore, the outlier detection was focused on $v$, and the method is expressed in the following equation:

$$
\begin{cases}v>120 \frac{\mathrm{mm}}{\mathrm{min}}, & \text { outliers, } \\ v \leq 120 \frac{\mathrm{mm}}{\mathrm{min}}, & \text { normal. }\end{cases}
$$

3.5.3. Section Segmentation. The ascending and stable sections of the cyclic tunneling process were obtained using the data extraction method, as expressed in equation (4). In many cases, the values of $v, F$, and $T$ in the ascending section are lower than those in the stable section, as shown in Figure 6. In this study, the mean value method was proposed for section segmentation in the ascending and stable sections. The above three parameters typically change together; therefore, a single value of $T$ is adopted to achieve section segmentation. When the time series $T$ is less than the mean value $T_{m}$, it should be regarded as an ascending section; otherwise, it is regarded as a stable section.

$$
\begin{cases}T>T_{m}, & \text { stable section, } \\ T \leq T_{m}, & \text { ascending section, }\end{cases}
$$

and

$$
T_{m}=\frac{1}{Q} \sum_{i=1}^{Q} T_{i},
$$

where $Q$ is the duration of the ascending and stable sections, $T_{m}$ is the mean value of $T$ in the ascending and stable sections, and $T_{i}$ represents the real-time $T$ in the ascending and stable sections.

3.5.4. Adjustment of the Ascending Section Data. From the characteristic analysis of the cyclic tunneling process in Figures 6 and 7, a $p$ value of less than $2 \mathrm{~mm} / \mathrm{r}$ implies an invalid rock mass fragmentation process. Therefore, the adjustment of ascending section data could adopt a method that can be expressed as follows:

$$
\left\{\begin{array}{l}
p<2 \frac{m m}{r}, \quad \text { invalid ascending section, } \\
p \geq 2 \frac{m m}{r}, \quad \text { valid ascending section. }
\end{array}\right.
$$

\section{Feature Expression for the TBM Cyclic Tunneling Process}

4.1. Feature Expression. The analysis presented in Section 3 showed that linear $F-p$ and $T-p$ relationships in the ascending sections are clear according to the field tunneling data and physical mechanism analysis. This concise and practical method avoids complex forms. The stable section is a special stage of the second stage of the ascending section. Therefore, three coefficients of the $F-p$ and $T-p$ relationships (i.e., $a, b$, and $k$ ) are introduced to express the characteristics of the rock mass fragmentation process as

$$
\left\{\begin{array}{l}
F=(a \cdot p+b) \cdot N, \\
T=k \cdot p \cdot N,
\end{array}\right.
$$

where $a$ and $b$ are the slope and intercept coefficients of the linear $F$ - $p$ relationship, with the units of $(\mathrm{kN} /$ cutter $) /(\mathrm{mm} / \mathrm{r})$ and $\mathrm{kN} /$ cutter, respectively; $k$ is the slope coefficient of the linear $T-p$ relationship with a unit of $(\mathrm{kNm} /$ cutter $) /(\mathrm{mm} / \mathrm{r})$; and the intercept of the linear $T$ - $p$ relationship can be ignored owing to the minor effect on the linear relationship [4].

Equation (9) is a simplified expression because it calculates the coefficients by directly averaging the total thrust and torque over the number of cutters, which may differ from equation (1). For example, the definition of single cutter torque and tangential force in the average torque of cutter head shows that the coefficient between the single cutter torque and tangential force is approximately 1.3 for this case. However, equation (9) can still be considered a secure and simple feature expression for the cyclic tunneling process owing to the calculation convenience compared with 
the expressions presented in $[33,34]$ without considering rock mass parameters.

4.2. Definition of Boring Indexes. Boring indexes are introduced to reflect the physical characteristics of the coefficients in the linear $F-p$ and $T-p$ relationships, which could reveal the law from the mechanism perspective of rock mass fragmentation and provide comprehensive information concerning the rock mass:

(1) Normal boring difficulty index, $a$ : the coefficient $a$ in the $F-p$ slope reflects the required increment of cutterhead thrust for a unit increment of penetration. A larger value corresponds to a harder rock mass to overcome the resistance for a unit increment of penetration, as reported in [24].

(2) Initial rock mass fragmentation difficulty index, $b$ : the coefficient $b$ in the $F-p$ intercept reflects the required cutterhead thrust for initial penetration, which supposing $p=0$ is related to the rock mass physical parameters [24]. Consequently, the rock mass is broken unless $p>p_{b}$ and $F>F_{b}$. However, $p_{b}$ is uncertain within the range of $1-2 \mathrm{~mm} / \mathrm{r}$ in this project, and $b$ is an intercept derived from the linear $F-p$ relationship, which can be conveniently determined. Meanwhile, the relationship between $F_{b}$ and $b$ can be expressed as $F_{b}=a \cdot p_{b}+b$; that is, $b$ is introduced in place of $F_{b}$.

(3) Tangential boring difficulty index, $k$ : the coefficient $k$ in the $T-p$ slope reflects the required increment of cutterhead torque for a unit increment of penetration [4]. A larger value indicates more energy consumed for fragmentation of a unit volume of rock mass.

Some of the many advantages of the three indexes are (a) higher accurate reflection of the rock mass characteristics, such as the physical parameters in a user-friendly manner [24]; (b) faster recognition of characteristics for the use of data in ascending section during the cyclic tunneling process; and (c) obtaining $F$ and $T$ at different $p$ values, which is crucial for adjusting and optimizing different operational parameters for safe and efficient tunneling.

4.3. Determination of Boring Indexes. The ascending section is the start of the valid cyclic tunneling process, the parameters of which have a large range from zero to a stable value, as shown in Figure 6. Section 3.5 presents the data processing method, where the ascending section data could be obtained readily. Thus, the boring indexes could be acquired through linear regression using the $F-p$ and $T-p$ data in ascending sections, which can quickly reflect the characteristics of the rock mass during tunneling. Therefore, the boring indexes were obtained. In general, the coefficient of determination $R^{2}$ of linear regression is introduced to select valid ascending section data, whereas $R^{2}$ is set to be greater than or equal to $0.6[4]$.
4.4. Influence of Boring Indexes in Different Rock Masses. Two sets of tunneling processes were selected, distributed between chainages $\mathrm{K} 64+310$ to $\mathrm{K} 64+304$ (Yanshanian granite) and $\mathrm{K} 65+483$ to $\mathrm{K} 65+478$ (Jurassic tuff), to analyze the influence of boring indexes in different rock masses. The length of each set of tunneling processes is approximately $5.3 \mathrm{~m}$, comprising three adjacent cyclic tunneling processes, within which the rock mass conditions of each set could be considered constant (Figure 11). Based on the flowchart presented in Figure 5, boring indexes are obtained in cyclic tunneling processes, as shown in Table 2.

Boring indexes $a, b$, and $k$ in the same set of cyclic tunneling sections can be regarded identical. For example, boring indexes in the three cyclic tunneling processes of each set have minor deviations, indicating that boring indexes are unique under the same rock mass conditions. Boring indexes differ for various rock masses, and each of their mean values exhibits a large deviation (Table 2). For example, the mean of index $a$ for each set is 9.5 and $8.1(\mathrm{kN} /$ cutter $) /(\mathrm{mm} / \mathrm{r})$, respectively, with a low absolute error of $1.4(\mathrm{kN} /$ cutter $) /(\mathrm{mm} /$ r) and relative error of $15 \%$. The mean of index $b$ is 192.6 and $115.3 \mathrm{kN} /$ cutter for each set, respectively, with a moderate absolute error of $77.3 \mathrm{kN} /$ cutter and relative error of $40 \%$. The mean of index $k$ for each set is 4.7 and $2.4(\mathrm{kNm} / \mathrm{cutter}) /$ $(\mathrm{mm} / \mathrm{r})$, respectively, with a high absolute error of $2.3(\mathrm{kNm} /$ cutter $) /(\mathrm{mm} / \mathrm{r})$ and relative error of approximately $100 \%$. These results confirm that boring indexes vary for different rock masses.

\subsection{Verification of Boring Indexes Using Performance Prediction}

4.5.1. Significance. The proposed boring indexes were verified using performance prediction to illustrate the rationality of the proposal. The calibration of model was performed using the data of $F, T$, and $p$ in the ascending section (linear relationships are proposed in (9)), and verification of the model was carried out using the data in the stable section of the same cyclic tunneling processes. The rock mass could be assumed identical for a cyclic tunneling stroke of approximately $1,800 \mathrm{~mm}$, as described in Section 4.4. However, it is difficult to determine the physical parameters of the rock mass in a timely manner, thus conventional methods [10-15] are difficult to be used for performance prediction. Based on the fine linear F- $p$ and $T-p$ relationships expressed by boring indexes in the ascending sections, as shown in Figure 7, accurate performance prediction models can be determined for the cyclic tunneling process.

Thus, boring indexes could be used for the following. (1) Adjusting the presetting operational parameters in stable sections in advance: different performance parameters can be obtained with various operational parameters, and TBM operators can select the proper operation parameters in stable sections based on the performance prediction models. (2) Optimizing operational parameters subjected to different constraint conditions: the performance prediction models provided relationships of different parameters, and TBM 


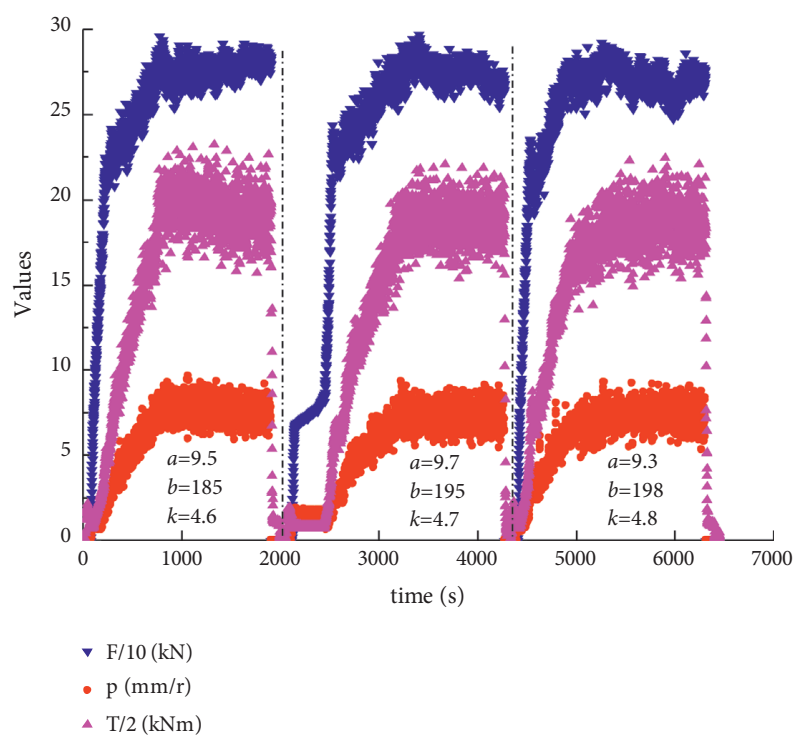

(a)

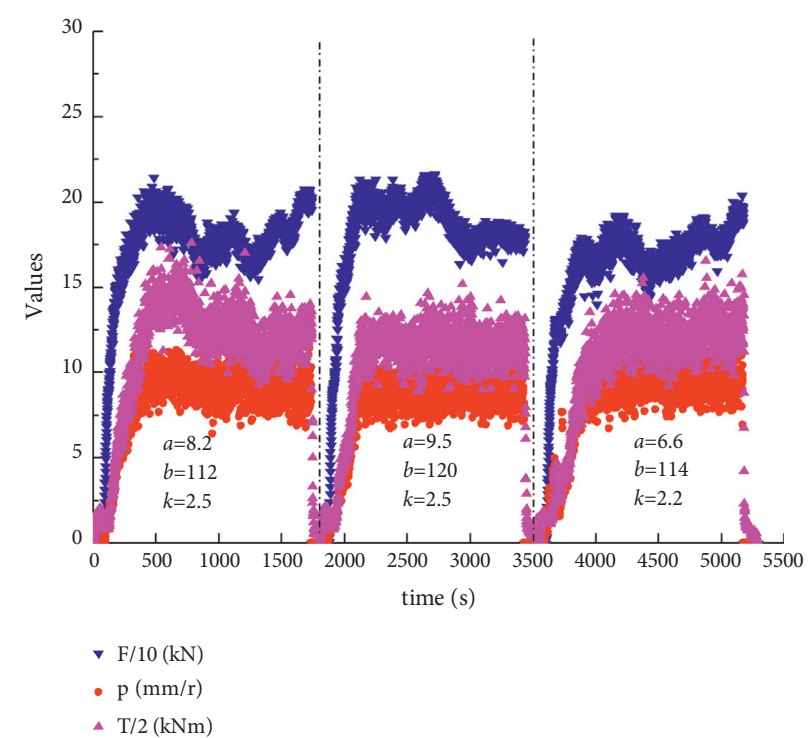

(b)

Figure 11: Boring indexes in different rock mass: (a) chainage 64310.1 to 64304.8 and (b) chainage 65483.6 to 65478.3.

TABLE 2: Boring indexes.

\begin{tabular}{lcccccc}
\hline & \multicolumn{5}{c}{ Boring indexes } \\
Row & \multicolumn{3}{c}{ K64 +310 to } & \multicolumn{3}{c}{ K65 + 483 to } \\
& \multicolumn{3}{c}{ K64 +304} & & & \\
& $a$ & $b$ & $k$ & $a$ & $b$ & $k$ \\
\hline 1 & 9.5 & 185 & 4.6 & 8.2 & 112 & 2.5 \\
2 & 9.7 & 195 & 4.7 & 9.5 & 120 & 2.5 \\
3 & 9.3 & 198 & 4.8 & 6.6 & 114 & 2.2 \\
Mean values & 9.5 & 192.6 & 4.7 & 8.1 & 115.3 & 2.4 \\
\hline
\end{tabular}

operators could optimize operational parameters using the maximum values of performance parameters. (3) Adverse geology conditions diagnosis: when the predicted and actual performance parameters have large prediction deviations in different operational parameters, there might be adverse geology conditions.

4.5.2. Main Characteristics of Boring Indexes for Performance Prediction. For the cyclic tunneling process in this project, boring indexes $a, b$, and $k$ were acquired for 291 cycles using the proposed method. The main characteristics are listed in Table 3 , in the range of $1.1-20.8(\mathrm{kN} /$ cutter $) /(\mathrm{mm} / \mathrm{r})$ for index $a, 79-224 \mathrm{kN} /$ cutter for index $b$, and $1.8-5.4(\mathrm{kNm} /$ cutter $) /(\mathrm{mm} / \mathrm{r})$ for index $k$, demonstrating some randomness and deviation, indicating some differences in rock mass during the TBM tunneling.

4.5.3. Model Evaluation Indicators. The evaluation indicators were introduced to assess the accuracy of performance prediction, as expressed in equation (10). Here, the mean absolute error (MAE) indicates the absolute error and mean absolute percentage error (MAPE) indicates the absolute percentage error of the actual and predicted performance parameters as follows:

$$
\left\{\begin{array}{l}
M A E=\frac{1}{N} \times \sum_{i=1}^{N}\left|y_{i}-\widehat{y}_{i}\right| \\
M A P E=\frac{1}{N} \times \sum_{i=1}^{N} \frac{\left|y_{i}-\widehat{y}_{i}\right|}{y_{i}} \times 100 \%
\end{array}\right.
$$

where $y_{i}$ is the actual performance parameter, $\hat{y}_{i}$ is the predicted performance parameter, and $N$ is the number of cyclic tunneling processes.

4.5.4. Performance Prediction. The mean values of $p, F$, and $T$ in stable sections of the cyclic tunneling process and the predicted values of $F$ and $T$ using boring indexes and $p$, as expressed in equation (9), are shown in Figure 12. The actual and predicted results for $F$ have an MAE and MAPE of $14.2 \mathrm{kN}$ and $6.7 \%$, respectively, indicating a close average predicted thrust to the actual values, with an error of $14.2 \mathrm{kN}$. The actual and predicted results of $T$ have an MAE and MAPE of $3.14 \mathrm{kNm}$ and $10.7 \%$, respectively. The obtained results could be attributed to the appropriateness of the linear of $F-p$ and $T-p$ relationships in ascending sections owing to a small error between actual and predicted performances.

\section{Support Measure Suggestions Based on Boring Indexes}

5.1. Significance. The TBM shield shown in this project has a length of 4,200 $\mathrm{mm}$, during which the rock mass cannot be directly observed; however, the quality of the rock mass on the shield surface and tunnel face is important for safety construction [35]. There are less significant methods for the real-time detection of rock mass on shield surfaces owing to the narrow space [36], and a quick diagnosis of adverse 
TABLE 3: Statistical results of the boring indexes.

\begin{tabular}{lcccccccc}
\hline Index & Mean & Std. & Min & 1st quartile & 2nd quartile & 3rd quartile & Max & Count \\
\hline$a$ & 10.8 & 3.2 & 1.1 & 8.6 & 10.8 & 12.8 & 20.8 \\
$b$ & 143.9 & 31.9 & 79.0 & 119.0 & 142.0 & 168.0 & 224.0 & 291 \\
$k$ & 3.5 & 0.9 & 1.8 & 2.8 & 3.6 & 4.3 & 5.4 & 291 \\
\hline
\end{tabular}

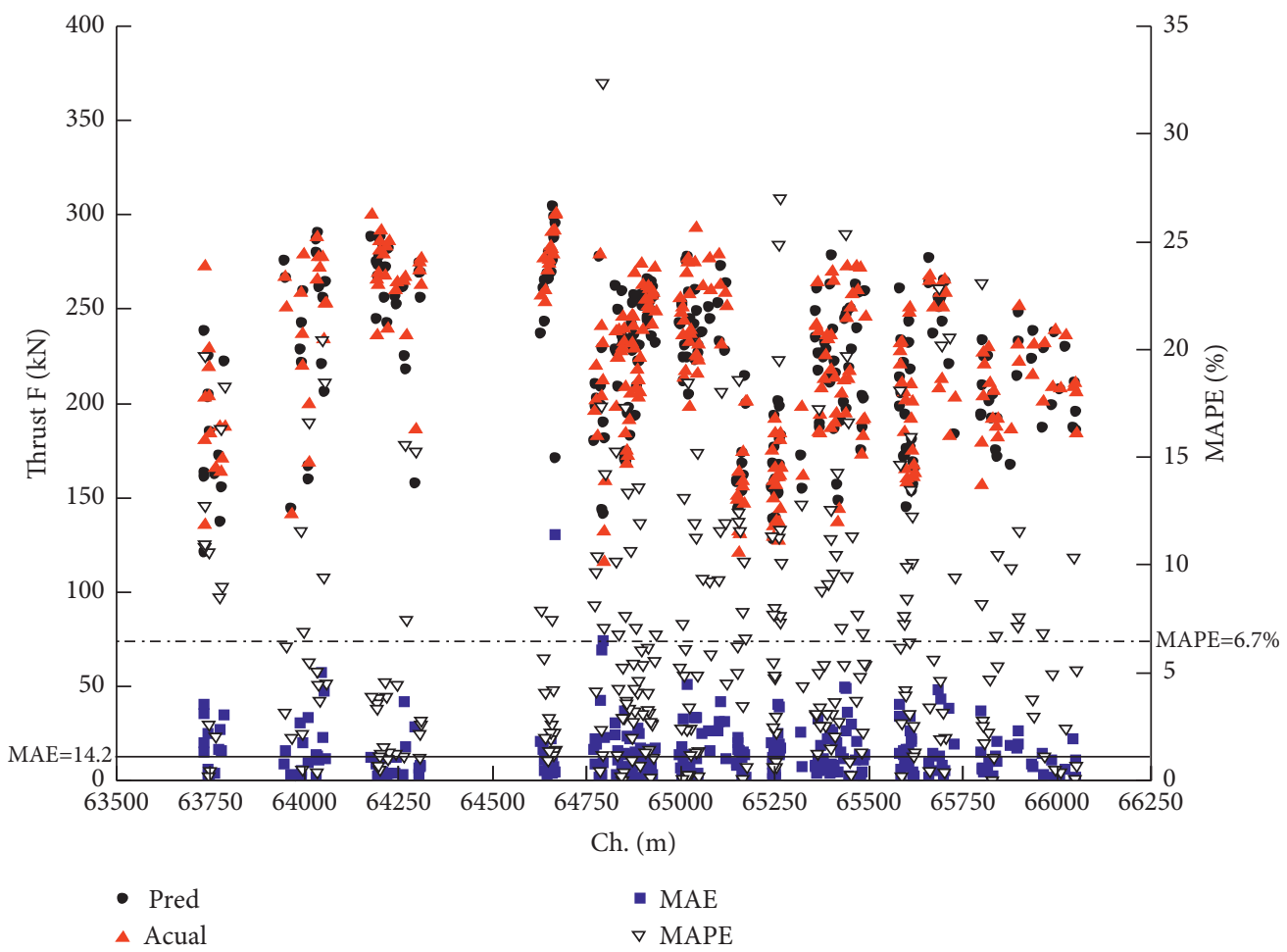

(a)

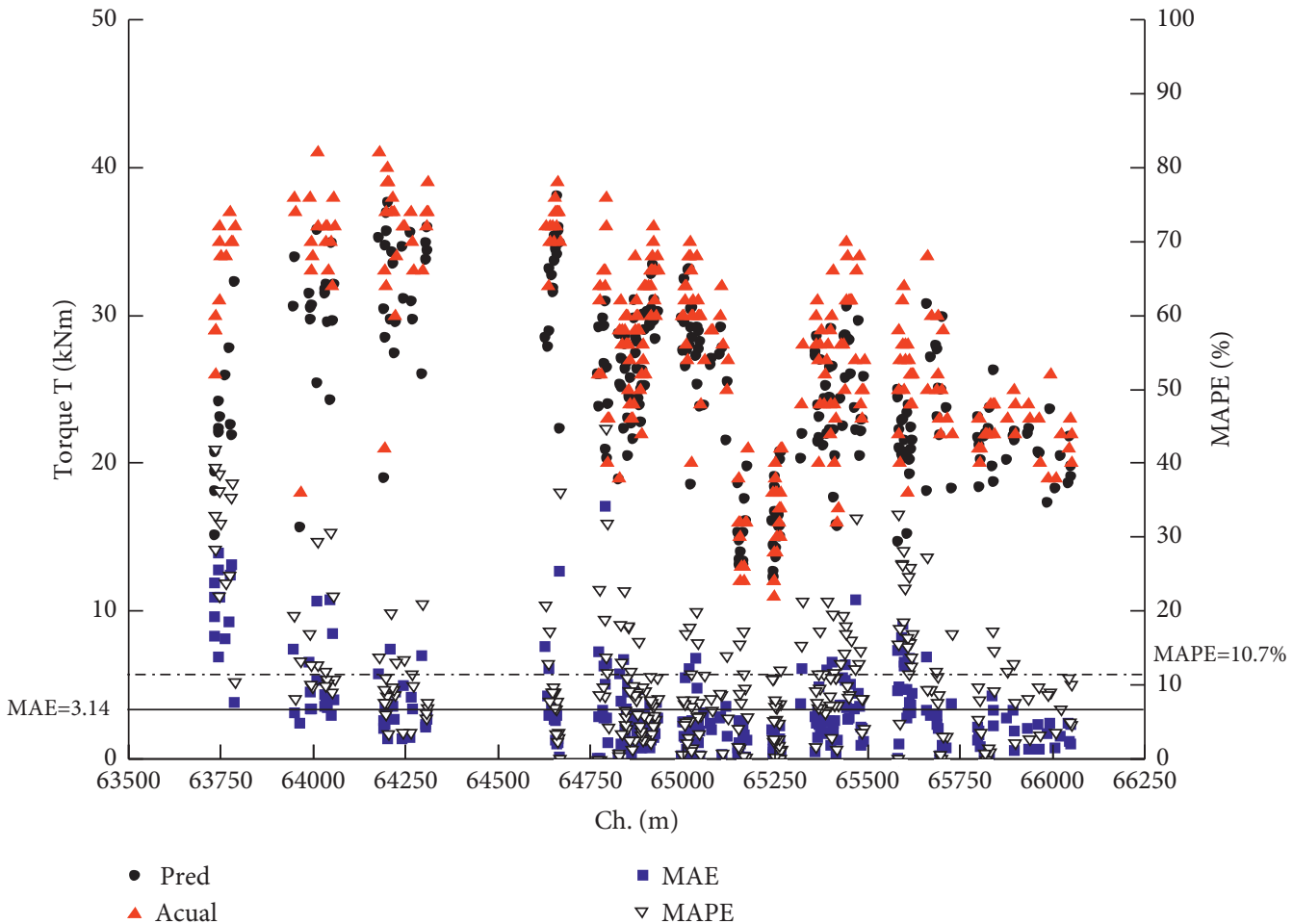

(b)

FIGURE 12: Performance prediction in different cyclic tunneling processes: (a) thrust prediction and (b) torque prediction. 
geology could be helpful for suggesting support measures during continuous tunneling. The tunneling data reflecting the rock mass could provide a useful method for adverse geological diagnosis and support measure suggestions.

5.2. Main Characteristics of Boring Indexes in Support Measures Sections. Table 4 presents geological descriptions of the 29 typical support measures sections and corresponding characteristics of boring indexes $a, b$, and $k$. Indeed, 133 valid cyclic tunneling processes exist in 29 typical support measures sections.

Table 5 presents the statistical results of boring indexes in the 29 typical support measures sections. The value of index $a$ is in the range of $1.1-16.5(\mathrm{kN} /$ cutter $) /(\mathrm{mm} / \mathrm{r})$, and the mean value is $7.89(\mathrm{kN} /$ cutter $) /(\mathrm{mm} / \mathrm{r})$, demonstrating a significant difference in various support measures sections. Meanwhile, the value of index $b$ is in the range of $89-146 \mathrm{kN} /$ cutter, and the mean value is $115 \mathrm{kN} /$ cutter, which is close to the friction thrust $\left(F_{f}=100 \mathrm{kN}\right)$, indicating that the rock mass can be easily broken after the cutterhead thrust exceeds the friction thrust. The value of index $k$ is in the range of $1.6-5.1(\mathrm{kNm} /$ cutter $) /(\mathrm{mm} / \mathrm{r})$, and the mean value is $2.9(\mathrm{kNm} /$ cutter $) /(\mathrm{mm} / \mathrm{r})$, demonstrating a significant difference in various support measures sections.

Table 6 presents the statistical results of boring indexes for 133 support measure processes. The total support sections have small randomness and variability in the range of 1.1-20.8 (kN/cutter $) /(\mathrm{mm} / \mathrm{r})$ for index $a, 85-219 \mathrm{kN} /$ cutter for index $b$, and $1.8-5.4(\mathrm{kNm} /$ cutter $) /(\mathrm{mm} / \mathrm{r})$ for index $k$. The distribution of boring indexes in the 133 support measure processes is similar to that of the 29 typical support measures sections.

5.3. Criterion for Support Measure Suggestions. In general, higher boring indexes mean more difficulty for rock mass fragmentation. Also, a criterion should be adopted to provide quantitative quotas for support measure suggestions; reasonable criterion could yield precise results. The selection of criterion is random and no theory. 3rd quartile, also called the larger quartile, is a widely used method to describe the distribution of data. In this study, a criterion for support measures is proposed based on the values of the $3 \mathrm{rd}$ quartile of boring indexes in the 29 typical support measures sections:

(1) The criterion for index $a$ adopts a $3^{\text {rd }}$ quartile value of $10.05(\mathrm{kN} /$ cutter $) /(\mathrm{mm} / \mathrm{r})$. It is advisable to conduct support measures when index $a$ is less than $10.05 \mathrm{kN} /$ cutter $/ \mathrm{mm} / \mathrm{r}$.

(2) The criterion for index $b$ adopts a $3^{\text {rd }}$ quartile value of $127 \mathrm{kN} /$ cutter. It is advisable to conduct support measures when index $b$ is less than $127 \mathrm{kN} /$ cutter.

(3) The criterion for index $k$ adopts a $3^{\text {rd }}$ quartile value of $3.3(\mathrm{kNm} /$ cutter $) /(\mathrm{mm} / \mathrm{r})$. It is advisable to conduct support measures when the index $k$ is less than 3.3 $(\mathrm{kNm} /$ cutter $) /(\mathrm{mm} / \mathrm{r})$.
Moreover, a parallel relationship exists between the three indexes, confirming that support measures should be implemented if one of the three indexes meets the requirements.

5.4. Model Evaluation Indicators. The criterion for support measure suggestions based on boring indexes is a classifier, and the adaptability of criterion can be assessed using indicators such as precision $(P)$, recall $(R)$, and $F_{1}$-score $\left(F_{1}\right)$, which are derived from indicators $P$ and $R$, where higher values of $F_{1}$ indicate higher accuracy of the classifier [37].

$$
\left\{\begin{array}{l}
P=\frac{T P}{T P+F P}, \\
R=\frac{T P}{T P+F N}, \\
F_{1}=\frac{2 \cdot P \cdot R}{P+R},
\end{array}\right.
$$

where $T P$ represents the number of actual and suggested truly support measures (suggested truly), FP is the number of actual and not suggested truly support measures (suggested incorrectly), and $F N$ is the number of actual but suggested falsely support measures (suggested falsely).

\subsection{Results of Support Measure Suggestions}

5.5.1. Suggestion Results Using One Single Index in the Entire Process. For the criterion mentioned in Section 5.3, boring indexes in the entire process (291 cycle processes in Section 4.5.2, which contains support and nonsupport measures) are analyzed for support measure suggestions, and the evaluation indicators are introduced to assess the accuracy. Figure 13 shows the characteristics of boring indexes along the tunnel and the criterion for different indexes.

The support measures identified using different index criteria in different lithologies are listed in Table 7, and the accuracies for different indicators are presented in Table 8 . According to Table 7, the total number of support measures in tuff lithology was 13 ; that is, TP- $a$ was $9, F P-a$ was 1 , and $F N-a$ was 4 , indicating 9 suggested truly, 1 suggested incorrectly, and 4 suggested falsely using index $a$, for a $P$ - $a$ of $90 \%, R-a$ of $69 \%$, and $F_{1}$ of $78 \%$. Specifically, $F_{1}$ is 35 and $74 \%$ using index $b$ and $k$, respectively, indicating that index $a$ has a higher accuracy based on $F_{1}$ in tuff lithology. In lava lithology, the total number of support measures was 57; that is, TP- $a$ was $50, F P-a$ was 13 , and $F N-a$ was 7 using index $a$, for a $P-a$ of $79 \%, R-a$ of $88 \%$, and $F_{1}$ of $83 \%$. In addition, $F_{1}$ is $78 \%$ using index $b$ and $k$; that is, index $a$ has a higher accuracy based on $F_{1}$ in lava lithology. In granite lithology, the total number of support measures was 67 , TP- $a$ was $37, F P-a$ was 7 , and $F N-a$ was 26 using index $a$, for a $P-a$ of $84 \%, R-a$ of $59 \%$, and $F_{1}$ of $69 \%$. In addition, $F_{1}$ is 54 and $63 \%$ using index $b$ and $k$, indicating that index $a$ has a higher accuracy based on $F_{1}$ in granite lithology. Furthermore, in lava lithology, evaluation indicators are higher compared to tuff and granite lithologies, confirming a higher suggested accuracy. 


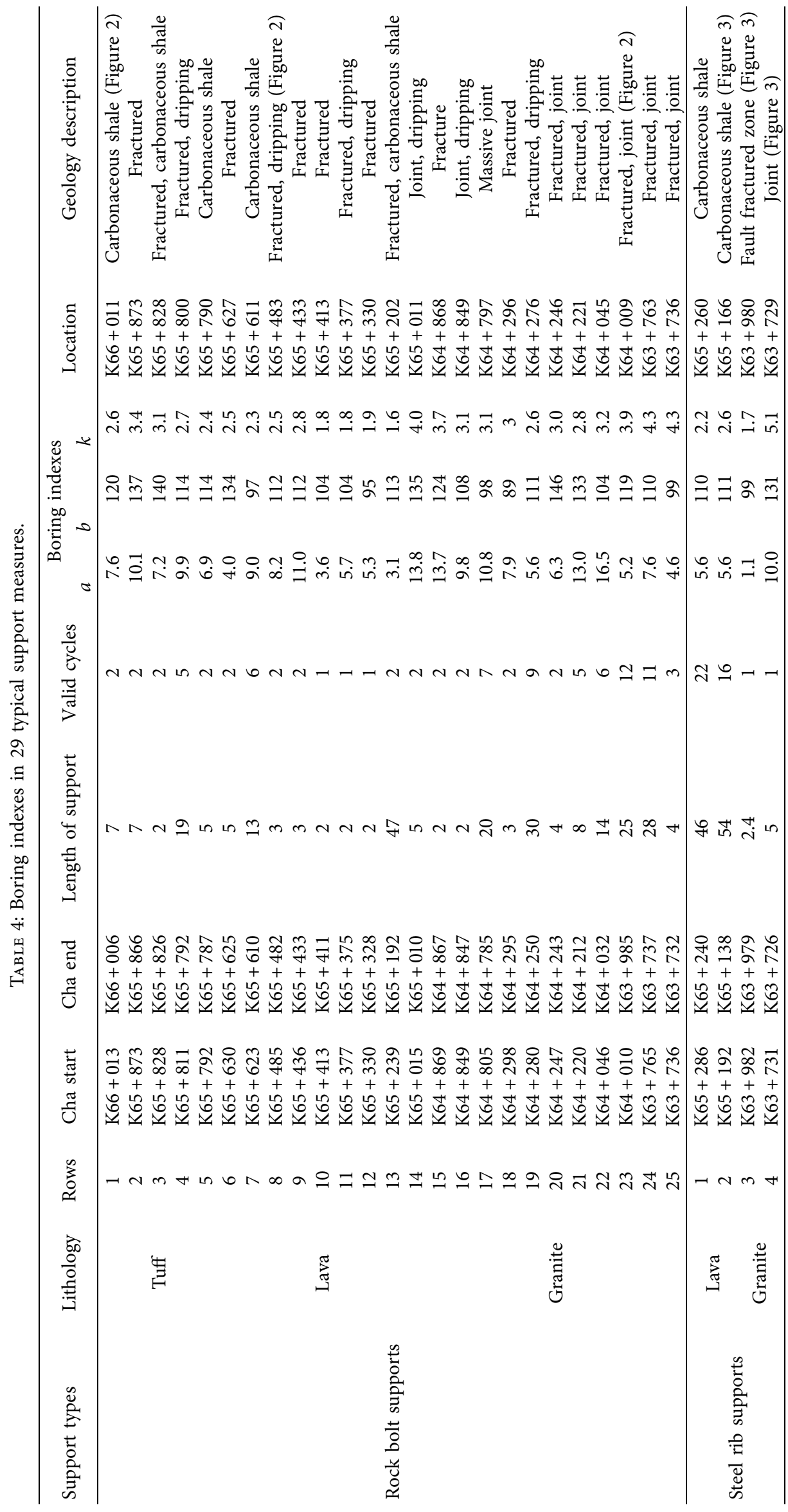


TABLE 5: Main characteristics of boring indexes of 29 typical support measures sections.

\begin{tabular}{lcccccccc}
\hline Index & Mean & Std. & Min & 1st quartile & 2nd quartile & 3rd quartile & Max & Count \\
\hline$a$ & 7.89 & 3.51 & 1.1 & 5.45 & 7.6 & 10.05 & 16.5 & 29 \\
$b$ & 115 & 14.7 & 89 & 104 & 112 & 127 & 146 & 29 \\
$k$ & 2.90 & 0.84 & 1.6 & 2.35 & 2.8 & 3.3 & 5.1 & 29 \\
\hline
\end{tabular}

TABLE 6: Statistical results of boring indexes in 133 support measures.

\begin{tabular}{lcccccccc}
\hline Index & Mean & Std. & Min & 1st quartile & 2nd quartile & 3rd quartile & Max & Count \\
\hline$a$ & 8.2 & 3.3 & 1.1 & 5.7 & 7.5 & 10.2 & 20.8 \\
$b$ & 129.7 & 31.7 & 85.0 & 105.0 & 124.0 & 144.5 & 219.0 & 133 \\
$k$ & 3.1 & 0.9 & 1.8 & 2.3 & 2.8 & 3.7 & 5.4 & 133 \\
\hline
\end{tabular}
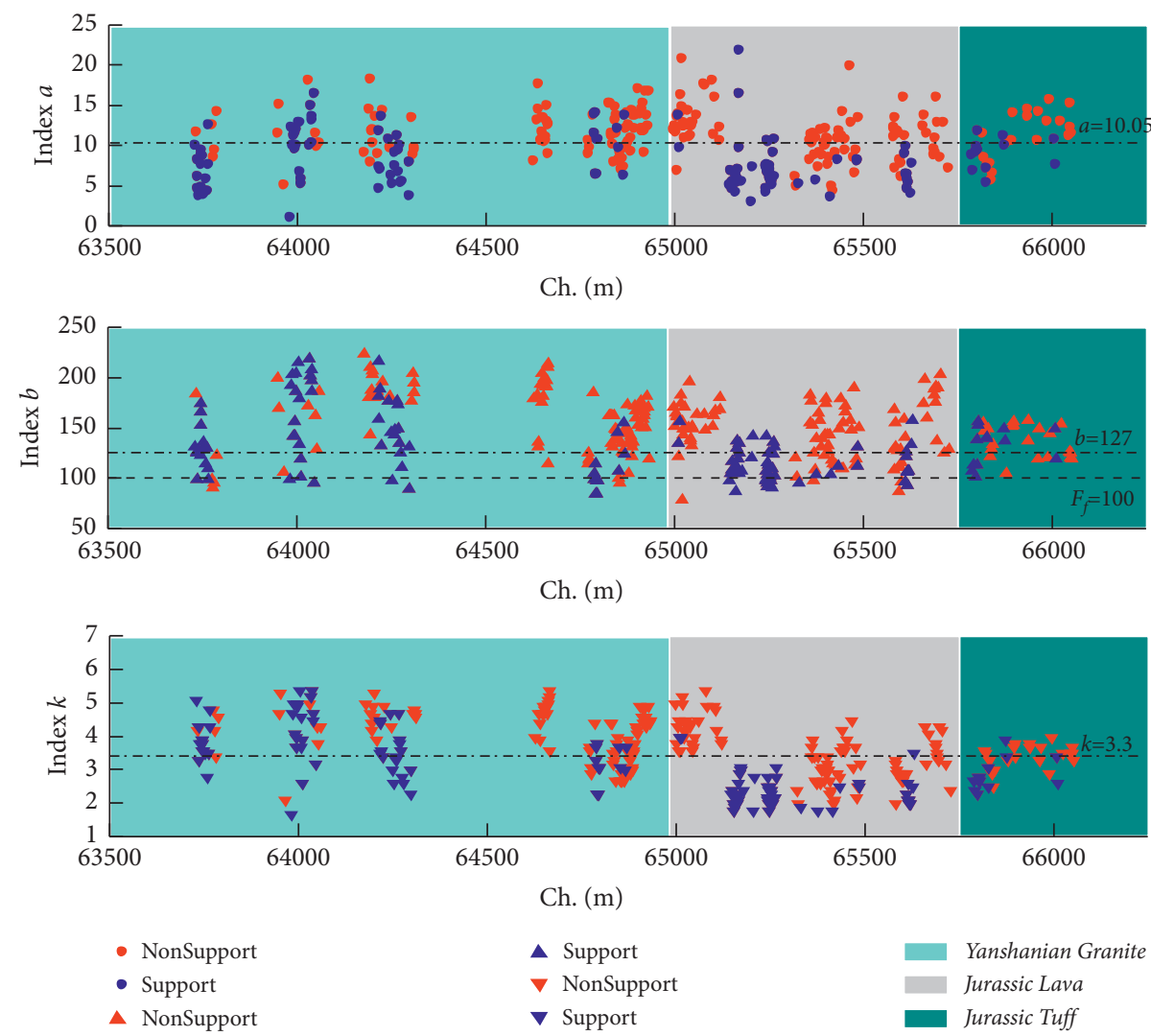

FigURE 13: Results of support measure suggestions using one single index.

TABLE 7: Results of support measure suggestions using one single index.

\begin{tabular}{|c|c|c|c|c|c|c|c|c|c|c|c|}
\hline \multirow[b]{2}{*}{ Lithology } & \multirow[b]{2}{*}{ Total number of cycles } & \multirow[b]{2}{*}{ Total number of support } & \multicolumn{9}{|c|}{ Suggestions results in the entire process } \\
\hline & & & $T P-a$ & $\begin{array}{c}F P- \\
a\end{array}$ & $F N-a$ & $T P-b$ & $\begin{array}{c}F P- \\
b\end{array}$ & $F N-b$ & $T P-k$ & $\begin{array}{c}F P- \\
k\end{array}$ & $F N-k$ \\
\hline Tuff & 28 & 13 & 9 & 1 & 4 & 4 & 6 & 9 & 10 & 4 & 3 \\
\hline Lava & 135 & 57 & 50 & 13 & 7 & 45 & 13 & 12 & 54 & 28 & 3 \\
\hline Granite & 128 & 63 & 37 & 7 & 26 & 24 & 10 & 39 & 16 & 11 & 47 \\
\hline
\end{tabular}

" $-a$ " indicates the result judged by index $a$, “- $b$ " indicates the result judged by index $b$, and " $-k$ " indicates the result judged by index $k$.

Therefore, Liujie et al. [24] proposed a linear regression relationship between index $a$ and $J_{v}$ rock mass volumetric joint count (number $/ \mathrm{m}^{3}$ ), expressed as $a=0.02 J_{v}^{2}-1.22 J_{v}$
+19.83 . Here, $J_{v}$ is greater than or equal to 0 , whereas a higher value of $J_{v}$ corresponds to a lower index $a$. In the support measures sections, as shown in Figures 2 and 3, many weak 
TABLE 8: Evaluation indicators using one single index.

\begin{tabular}{llllllllll}
\hline \multirow{2}{*}{ Lithology } & \multicolumn{1}{c}{ Evaluation indicators } \\
& $P-a(\%)$ & $R-a(\%)$ & $F_{1}-a(\%)$ & $P-b(\%)$ & $R-b(\%)$ & $F_{1}-b(\%)$ & $P-k(\%)$ & $R-k(\%)$ & $F_{1}-k(\%)$ \\
\hline Tuff & 90 & 69 & 78 & 40 & 31 & 35 & 71 & 77 \\
Lava & 79 & 88 & 83 & 78 & 79 & 78 & 66 & 95 \\
Granite & 84 & 59 & 69 & 71 & 38 & 49 & 59 & 25 \\
Average & 84 & 72 & 77 & 63 & 49 & 54 & 65 & 66 \\
\hline
\end{tabular}
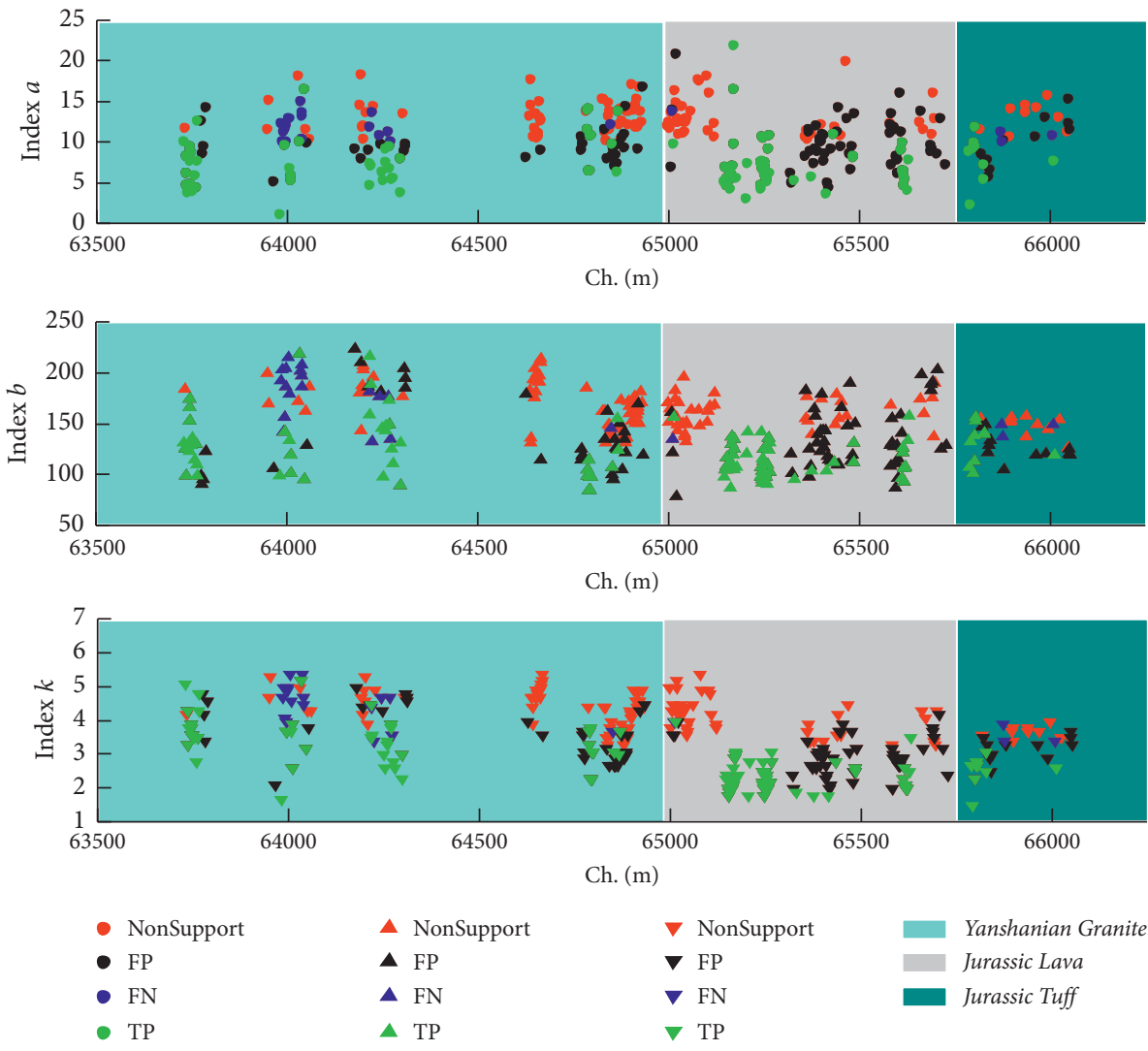

FIGURE 14: Results of support measure suggestions using a combination of the three indexes.

and fragmented rock masses exist, which contain the number of joints accompanied by increased $J_{v}$. Thus, index $a$ in the support measures sections has lower values, which achieved better results for support measure suggestions using index $a$.

5.5.2. Suggestions Results Using Three Indexes in the Entire Process. One single index may adversely influence other indexes; a combination of three indexes, where all indexes should meet the criterion for support measures, is conducted to examine the results compared to that of a single index. Figure 14 shows the results of a combination of the three indexes, whereas the accuracies are presented in Table 9.

For the 13 support measures in tuff lithology, $T P$ was $10, F P$ was 7 , and $F N$ was 3, indicating 10 suggested truly, 7 suggested incorrectly, and 3 suggested falsely using a combination of the three indexes, for a $P$ of $59 \%, R$ of $77 \%$, and $F_{1}$ of $67 \%$. For the 57 support measures in lava lithology, TP was 56, FP was 36, and $F N$ was 1 , for $P=61 \%, R=98 \%$, and $F_{1}=75 \%$. For the 63 support measures in granite lithology, $T P=45, F P=14$, and $F N=18$, for $P=76 \%, R=71 \%$, and $F_{1}=74 \%$.

Compared with results listed in Tables 7 and 8, Table 9 shows better suggestion results in granite lithology, with $F_{1}$ of $74 \%$ using a combination of three indexes and 69,49 , and $36 \%$ using a single index, where accuracies were highly enhanced. However, in tuff and lava lithologies, TP and FP exhibited a slight enhancement, resulting in a higher $R$, lower $P$, and lower $F_{1}$ compared with that of a single index. All the achieved results indicate that a combination of the three indexes could improve the accuracy of support measure suggestions in granite lithology. However, slight changes in tuff and lava lithologies occur, and index $a$ could still acquire better accuracy suggestions in tuff and lava lithologies.

\section{Discussion}

Boring indexes reflect three characteristics of rock mass fragmentation precisely. Therefore, we proposed a 
TABLE 9: Results and evaluation indicators using a combination of the three indexes.

\begin{tabular}{lccccccc}
\hline \multirow{2}{*}{ Lithology } & \multirow{2}{*}{ Total number of cycles } & \multirow{2}{*}{ Total numberof support } & \multicolumn{4}{c}{ Suggestions results in the entire process } \\
& & & $F P$ & $F N$ & $P(\%)$ & $R(\%)$ & $F_{1}(\%)$ \\
\hline Tuff & 28 & 13 & 10 & 7 & 3 & 59 & 77 \\
Lava & 135 & 57 & 56 & 36 & 1 & 61 & 98 \\
Granite & 128 & 63 & 45 & 14 & 18 & 76 & 71 \\
\hline
\end{tabular}

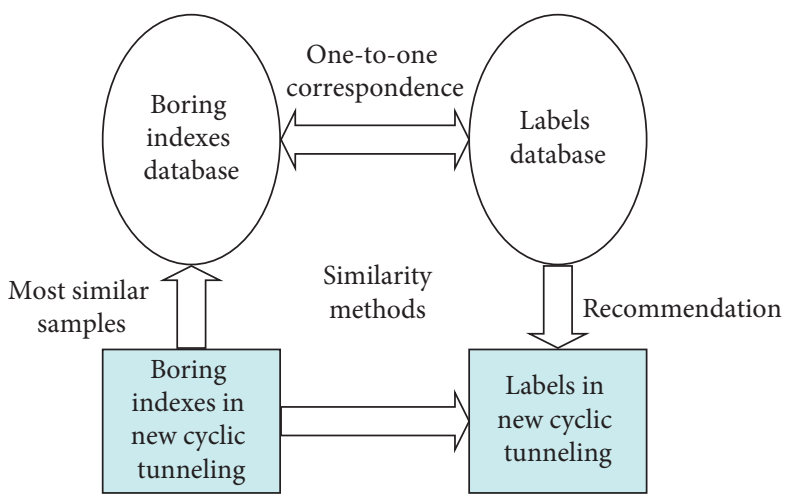

FIgURE 15: TBM recommendation systems for different goals based on boring indexes.

preliminary application for support measure suggestions based on the statistical features of boring indexes.

The recommended operational parameters for AIaided tunneling are shown in Figure 15. The similarity methods of boring indexes, such as cosine and Euclidean distance similarities, were used to select the maximum similarity samples from the set of samples and actual operating values, such as cutterhead rotation speed $n$ and advance rate $v$, whereas the controlling parameters could be set as the corresponding values of the similarity samples.

$$
v_{\max }=n \cdot p_{\max }=n \cdot \min \left(\frac{F_{\max }-b}{a}, \frac{T_{\max }}{k}, \frac{v_{\max }}{n}\right) .
$$

Moreover, the operational parameters for manual operation tunneling (expressed in equation (12)) were optimized. The optimum control parameters are effective for improving the advance rate, and the use of boring indexes to predict cutterhead thrust and torque provides a reasonable choice for selecting the advance rate $v$, which could achieve promising optimization results during manual operation tunneling.

In addition, rock masses can be classified using different project data (Figure 15). Determining the classification of rock mass is based on the actual situation of rock mass and experience of construction workers. Furthermore, many uncertain factors exist because of the complexity of the rock mass and subjectivity of humanity, and quantitative indexes are required to accurately assess the classification. The described similarity methods of using boring indexes to identify the similarity samples from different projects could determine the best matching rock mass and improve the accuracy and operability in rock mass classification, as shown in Figure 15.

\section{Conclusions}

(1) The second stages of ascending sections $(p \geq 2 \mathrm{~mm} / \mathrm{r})$ are valid fragmentation processes, and the first stages of ascending sections $(p<2 \mathrm{~mm} / \mathrm{r})$ are invalid fragmentation processes in the Yinchao TBM project. Linear $F-p$ and $T$ - $p$ relationships in the second stages of ascending sections are more appropriate for the expression of valid fragmentation processes.

(2) Boring indexes derived from the coefficient of linear $F-p$ and $T-p$ relationships could illustrate the features during TBM-rock mass fragmentation. For instance, index $a$ reflects the initial rock mass fragmentation difficulty, index $b$ reflects the normal boring difficulty, and index $k$ reflects the tangential boring difficulty.

(3) Boring indexes could be used for support measure suggestions, with criterion values of $10.05(\mathrm{kN} /$ cutter $) /(\mathrm{mm} / \mathrm{r}), 127 \mathrm{kN} /$ cutter, and $3.3(\mathrm{kNm} /$ cutter $) /(\mathrm{mm} / \mathrm{r})$ for indexes $a, b$, and $k$, respectively, whereas support measures should be adopted when boring indexes are lower than the criterion.

\section{Data Availability}

The data used to support the findings of this study are available from the corresponding author upon request. 


\section{Conflicts of Interest}

The authors declare that there are no conflicts of interest in this publication.

\section{Acknowledgments}

The authors sincerely thank the China Railway Engineering Equipment Group Corporation and the Survey and Design Institute of Water Conservancy of Jilin Province for the data support. This work was financially supported by grants from the Key Research Project of SINOHYDRO Corporation Limited (Grant no. DJ-ZDXM-2019-10), National Natural Science Foundation of China (Grant no. 51879284), and Natural Science Foundation of Shaanxi Province (Grant nos. 2019JLZ-13, 2019JLP-23, and 2017SLKJ-26).

\section{References}

[1] L. Jianbin, J. Liujie, Z. Xiaofeng, L. Pengyu, and Y. Chen, "Application and outlook of information and intelligence technology for safe and efficient TBM construction," Tunnelling and Underground Space Technology, vol. 93, Article ID 103097, 2019.

[2] K. Chmelina, K. Rabensteiner, and G. Krusche, "A tunnel information system for the management and utilization of geo-engineering data in urban tunnel projects," Geotechnical \& Geological Engineering, vol. 31, no. 3, pp. 845-859, 2013.

[3] L. Jinhui, L. Pengxi, G. Dong, L. Xu, and C. Zuyu, "Advanced prediction of tunnel boring machine performance based on big data," Geoscience Frontiers, vol. 12, no. 1, pp. 331-338, 2021.

[4] C. Zuyu, Z. Yunpei, L. Jianbin, L. Xu, and J. Liujie, "Diagnosing tunnel collapse sections based on TBM tunneling big data and deep learning: a case study on the Yinsong Project, China," Tunnelling and Underground Space Technology, vol. 108, Article ID 103700, 2021.

[5] Q. M. Gong, J. Zhao, and Y. S. Jiang, "In situ TBM penetration tests and rock mass boreability analysis in hard rock tunnels," Tunnelling and Underground Space Technology, vol. 22, no. 3, pp. 303-316, 2007.

[6] R. Gertsch, L. Gertsch, and J. Rostami, "Disc cutting tests in Colorado red granite: implications for TBM performance prediction," International Journal of Rock Mechanics and Mining Sciences, vol. 44, no. 2, pp. 238-246, 2007.

[7] A. Salimi, J. Rostami, C. Moormann, and A. Delisio, “Application of non-linear regression analysis and artificial intelligence algorithms for performance prediction of hard rock TBMs," Tunnelling and Underground Space Technology, vol. 58, pp. 236-246, 2016.

[8] C. Balci, "Correlation of rock cutting tests with field performance of a TBM in a highly fractured rock formation: a case study in Kozyatagi-Kadikoy metro tunnel, Turkey," Tunnelling and Underground Space Technology, vol. 24, no. 4, pp. 423-435, 2009.

[9] Q. M. Gong, J. Zhao, and A. M. Hefny, "Numerical simulation of rock fragmentation process induced by two TBM cutters and cutter spacing optimization," Tunnelling and Underground Space Technology, vol. 21, no. 3, p. 263, 2006.

[10] J. A. Danial, K. Mohammadreza, M. Aminaton, and Y. Saffet, "Application of several optimization techniques for estimating TBM advance rate in granitic rocks," Journal of Rock
Mechanics and Geotechnical Engineering, vol. 11, no. 4, pp. 779-789, 2019.

[11] J. A. Danial, M. Edy, N. Mogana, N. Nobuya, and Y. Saffet, "Development of hybrid intelligent models for predicting TBM penetration rate in hard rock condition," Tunnelling and Underground Space Technology, vol. 63, pp. 29-43, 2017.

[12] A. Khetwal, J. Rostami, and P. P. Nelson, "Investigating the impact of TBM downtimes on utilization factor based on sensitivity analysis," Tunnelling and Underground Space Technology, vol. 106, p. 103586, 2020.

[13] S. Yagiz, "Utilizing rock mass properties for predicting TBM performance in hard rock condition," Tunnelling and Underground Space Technology, vol. 23, no. 3, pp. 326-339, 2008.

[14] Y. Saffet, G. Candan, S. Ebru, and I. Serdar, "Application of two non-linear prediction tools to the estimation of tunnel boring machine performance," Engineering Applications of Artificial Intelligence, vol. 22, pp. 808-814, 2009.

[15] Z. Jian, Q.. Yingui, Z. Shuangli et al., "Optimization of support vector machine through the use of metaheuristic algorithms in forecasting TBM advance rate," Engineering Applications of Artificial Intelligence, vol. 97, Article ID 104015, 2020.

[16] E. Khalid, S. ShuiLong, Z. Annan, S. Wenjuan, and Y. Zhenyu, "Prediction model of shield performance during tunnelling via incorporating improved particle swarm optimization into ANFIS," IEEE Access, vol. 8, pp. 39659-39671, 2020.

[17] L. Xiaoxue, S. Shui-Long, X. Yeshuang, and Z. Annan, "Nonlinear spring model for backfill grout-consolidation behind shield tunnel lining," Computers and Geotechnics, vol. 136, Article ID 104235, 2021.

[18] Z. Ning, Z. Annan, P. Yutao, and S. ShuiLong, "Measurement and prediction of tunnelling-induced ground settlement in karst region by using expanding deep learning method," Measurement, vol. 183, Article ID 109700, 2021.

[19] L. Quansheng, L. Jianping, P. Yucong, K. Xiaoxuan, and H. Kairong, "A case study of TBM performance prediction using a Chinese rock mass classification system - hydropower Classification (HC) method," Tunnelling and Underground Space Technology, vol. 65, pp. 140-154, 2017.

[20] E. Farrokh, J. Rostami, and C. Laughton, "Study of various models for estimation of penetration rate of hard rock TBMs," Tunnelling and Underground Space Technology, vol. 30, no. 4, pp. 110-123, 2012.

[21] J. Hassanpour, J. Rostami, and J. Zhao, "A new hard rock TBM performance prediction model for project planning," Tunnelling and Underground Space Technology, vol. 26, no. 5, pp. 595-603, 2011.

[22] L. Quansheng, W. Xinyu, H. Xing, and Y. Xin, "Prediction model of rock mass class using classification and regression tree integrated AdaBoost algorithm based on TBM driving data," Tunnelling and Underground Space Technology, vol. 106, Article ID 103595, 2020.

[23] P. Yucong, L. Quansheng, L. Jianping, L. Qi, and K. Xiaoxuan, "Full-scale linear cutting tests in Chongqing Sandstone to study the influence of confining stress on rock cutting efficiency by TBM disc cutter," Tunnelling and Underground Space Technology, vol. 80, pp. 197-210, 2018.

[24] J. Liujie, L. Jianbin, Y. Chen, C. Shuai, Z. Na, and P. Xingxin, "A case study of TBM performance prediction using field tunnelling tests in limestone strata," Tunnelling and Underground Space Technology, vol. 83, pp. 364-372, 2019.

[25] J. Gallwey, M. Eyre, and J. Coggan, "A machine learning approach for the detection of supporting rock bolts from laser scan data in an underground mine," Tunnelling and Underground Space Technology, vol. 107, Article ID 103656, 2021. 
[26] M. I. Alvarez-Fernandez, M. B. Prendes-Gero, J. M. Drouet, F. Lopez-Gayarre, and J. Rodriguez-Vigil Junco, "Application of genetic algorithms in the optimisation of steel rib supports," Tunnelling and Underground Space Technology, vol. 103, Article ID 103462, 2020.

[27] A. Benato and P. Oreste, "Prediction of penetration per revolution in TBM tunneling as a function of intact rock and rock mass characteristics," International Journal of Rock Mechanics and Mining Sciences, vol. 74, pp. 119-127, 2015.

[28] J. Liujie, L. Jianbin, Z. Na, C. Shuai, Y. Chen, and C. Hongbo, "A TBM advance rate prediction method considering the effects of operating factors," Tunnelling and Underground Space Technology, vol. 107, Article ID 103620, 2021.

[29] X. Yadong, Z. Jie, L. Chun, S. Mahdi, and Z. Jie, "Rock fragmentation induced by a TBM disc-cutter considering the effects of joints: a numerical simulation by DEM," Computers and Geotechnics, vol. 136, Article ID 104230, 2021.

[30] W. YuJie, Y. JianHua, and C. Zuyu, "Calculation of bearing capacity of a strip footing using an upper bound method," International Journal for Numerical and Analytical Methods in Geomechanics, vol. 25, pp. 841-851, 2001.

[31] J. Rostami and L. Ozdemir, "New model for performance production of hard rock TBMs," in Proceedings - Rapid Excavation and Tunneling Conference, pp. 793-809, Springer, Boston, MA, USA, January 1993.

[32] Z. Qianli, L. Zhenyu, and J. Tan, "Prediction of geological conditions for a tunnel boring machine using big operational data," Automation in Construction, vol. 100, pp. 73-83, 2019.

[33] F. F. Roxborough and H. R. Phillips, "Rock excavation by disc cutter," International Journal of Rock Mechanics and Mining Science \& Geomechanics Abstracts, vol. 12, no. 12, pp. 361-366, 1975.

[34] K. Fukui and S. Okubo, "Some attempts for estimating rock strength and rock mass classification from cutting force and investigation of optimum operation of tunnel boring machines," Rock Mechanics and Rock Engineering, vol. 39, no. 1, pp. 25-44, 2006.

[35] J. Ji, Z. Zhang, Z. Wu, J. Xia, Y. Wu, and Q. Lü, “An efficient probabilistic design approach for tunnel face stability by inverse reliability analysis," Geoscience Frontiers, vol. 12, no. 5, Article ID 101210, 2021.

[36] K. Ranjan, M. Prabhat Kumar, N.. Ashish, and D. Arka Jyoti, "Evaluation of load transfer mechanism under axial loads in a novel coupler of dual height rock bolts," International Journal of Mining Science and Technology, vol. 31, no. 2, pp. 225-232, 2021.

[37] L. Zaobao, L. Long, F.. Xingli et al., "Hard-rock tunnel lithology prediction with TBM construction big data using a global-attention-mechanism-based LSTM network," Automation in Construction, vol. 125, Article ID 103647, 2021. 